\title{
Heavy chain-1 of inter- $\alpha$-inhibitor has an integrin-like structure with immune regulatory activities
}

David C. Briggs ${ }^{1,4}$, Alexander W.W. Langford-Smith ${ }^{1,5}$, Thomas A. Jowitt ${ }^{1,3}$, Cay M. Kielty ${ }^{1}$, Jan J. Enghild $^{6}$, Clair Baldock ${ }^{1,3}$, Caroline M. Milner ${ }^{2,3}$, and Anthony J. Day ${ }^{1,2,3}$

\author{
${ }^{1}$ Wellcome Trust Centre for Cell-Matrix Research, ${ }^{2}$ Lydia Becker Institute of Immunology and \\ Inflammation, ${ }^{3}$ Division of Cell-Matrix Biology \& Regenerative Medicine, School of Biological Sciences, \\ Faculty of Biology, Medicine \& Health, University of Manchester, Manchester Academic Health Science \\ Centre, Oxford Road, Manchester M13 9PT, UK \\ ${ }^{4}$ Current address: The Francis Crick Institute, 1 Midland Rd, London, NW1 1AT, UK \\ ${ }^{5}$ Current address: Translational Cardiovascular Science, The Centre for Bioscience, Manchester Metropolitan \\ University, Manchester, M1 5GD, UK \\ ${ }^{6}$ Department of Molecular Biology and Genetics, University of Aarhus, 8000 Aarhus C, Denmark \\ ${ }^{7}$ Corresponding author. Email: Anthony.day@manchester.ac.uk; tel: +44 (0)161 2751495
}

\begin{abstract}
Inter- $\alpha$-inhibitor $(\mathrm{I} \alpha \mathrm{I})^{1}$ is a proteoglycan essential for mammalian reproduction that also plays a less wellcharacterised role in inflammation. I $\alpha$ I is composed of 2 homologous 'heavy chains' (HC1 and HC2) covalently attached to chondroitin sulphate on the bikunin core protein. Prior to ovulation HCs are transferred onto the polysaccharide hyaluronan (HA), thereby stabilising a matrix that is required for fertilisation. Here we show that human $\mathrm{HC} 1$ has a structure similar to integrin $\beta$-chains and contains a functional MIDAS (metal ion-dependent adhesion site) motif that can mediate self-association of heavy chains, providing a mechanism for matrix crosslinking. Surprisingly, its interaction with RGD-containing integrin ligands, such as vitronectin and the latency-associated peptides of TGF $\beta$, occurs in a MIDAS/cationindependent manner. However, HC1 utilises its MIDAS motif to bind to, and inhibit the cleavage of, complement $\mathrm{C} 3$, thus identifying it as a novel regulator of innate immunity through inhibition of the alternative pathway $\mathrm{C} 3$ convertase.
\end{abstract}

\section{${ }^{1}$ Abbreviations}

ADPs, atomic displacement parameter; AUC, analytical ultracentrifugation; CMG2, capillary morphogenesis protein-2; COC, cumulus-oocyte complex; CS, chondroitin sulphate; FB, complement factor B; FnIII; fibronectin type III; HA, hyaluronan; HC, heavy chain; $\mathrm{HC} \cdot \mathrm{HA}$, covalent complex of $\mathrm{HC}$ with $\mathrm{HA}$; I $\alpha \mathrm{I}$, inter- $\alpha$-inhibitor; ITGA, integrin $\alpha$-chain; ITGB, integrin $\beta$-chain; LAP, latency associated peptide; LLC, large latent complex; LTBP, latent TGF $\beta$ binding protein; MIDAS, metal ion-dependent adhesion site; P $\alpha$, pre- $\alpha$-inhibitor; PTX3, pentraxin-3; rHC1, recombinant HC1; SAXS, small-angle X-ray scattering; SHAP, serum-derived HA binding protein; SLC, small latent complex; TEM8, tumour endothelial marker-8; TGF $\beta$, transforming factor $\beta$; TSG-6, tumour necrosis factor-stimulated gene-6; TSG- $6 \bullet \mathrm{HC}$, covalent complex of TSG-6 and HC; vWFA domain, von Willebrand Factor A domain. 


\section{Introduction}

Inter-alpha-inhibitor $(\mathrm{I} \alpha \mathrm{I})$ is an unusual plasma proteoglycan, comprised of 3 protein chains covalently linked via a chondroitin-sulphate (CS) glycosaminoglycan (GAG) chain (Enghild et al., 1989); see Supplementary Figure 1A. The CS chain is attached via a typical tetrasaccharide linkage to the core protein, bikunin. The protein products of the ITIH1 and ITIH2 genes, termed heavy chain 1 (HC1) and HC2, are covalently attached via ester bonds linking their C-termini to C6 hydroxyl-groups on the N-acetyl galactosamine sugars within the CS chain (Enghild et al., 1993; Morelle et al., 1994). HC2 is positioned closer to bikunin than $\mathrm{HC1}$, and the two HCs are attached to sugars 1-2 disaccharides apart (Enghild et al., 1999; Ly et al., 2011).

$\mathrm{HC} 1$ and $\mathrm{HC} 2$ are approximately $80 \mathrm{kDa}$ in size and share $\sim 39 \%$ sequence identity. They are synthesised with C-terminal pro-domains (of 239 and 244 amino acid residues, respectively) that are cleaved when the HCs are covalently attached to the bikunin CS chain (Kaczmarczyk et al., 2002; Zhuo et al., 2004); HC3 (ITIH3; 54\% identical to HC1) can also link to the bikunin CS proteoglycan (Supplementary Figure 1A), to form pre-alpha-inhibitor (PaI) (Enghild et al., 1989, 1991), and there is evidence that the related HC5, and likely HC6 (but not HC4), can also become attached to CS in this way (Day and Milner, 2019; Martin et al., 2016). All HCs are predicted to contain a single von Willebrand factor type-A (vWFa) domain, which makes up roughly the central one-third of the amino acid sequence. The flanking sequences are not homologous to any known domain.

I $\alpha$ I plays a critical role in mammalian reproductive biology such that female mice with the bikunin gene deleted, and consequently lacking I $\alpha \mathrm{I}$ and PaI, are infertile (Sato et al., 2001; Zhuo et al., 2001). This is due to the impaired formation of the cumulus extracellular matrix that normally drives the expansion of the cumulus-oocyte-complex (COC). This elastic matrix (Chen et al., 2016) protects the oocyte during the expulsion of the $\mathrm{COC}$ from the follicle and also provides a large surface area facilitating sperm capture in vivo (Nagyova, 2015; Russell and Salustri, 2006). The cumulus matrix is rich in the non-sulphated GAG hyaluronan (HA), where this high molecular weight polysaccharide becomes modified by the covalent attachment of HC1, HC2 and HC3 (Mukhopadhyay et al., 2001). Here, TSG-6, a protein that is expressed by the cumulus cells, plays a catalytic role in transferring the HCs from the CS chains of I $\alpha$ I and P $\alpha$ I onto HA to form HC $\cdot H A$ (aka SHAP-HA) complexes (Day and Milner, 2019; Rugg et al., 2005). TSG-6 also mediates the formation of $\mathrm{HC} \cdot \mathrm{HAs}$ during inflammation, when $\mathrm{I} \alpha \mathrm{I} / \mathrm{P} \alpha \mathrm{I}$ leak into tissues from the circulation. rheumatoid arthritis patients, where on average 3 to $5 \mathrm{HCs}$ are attached to an HA chain of $\sim 2 \mathrm{MDa}$, the polysaccharide is more aggregated compared to unmodified HA (Yingsung et al., 2003); this has been attributed to crosslinking of $\mathrm{HC} \cdot \mathrm{HA}$ complexes via interactions between $\mathrm{HCs}$ based on their apparent associations visualised by electron microscopy. Given that $\mathrm{HC} 1, \mathrm{HC} 2$ and $\mathrm{HC} 3$ can all be transferred onto HA during arthritis (Zhao et al., 1995) such crosslinking could be mediated by homotypic and/or heterotypic 
$\mathrm{HC}-\mathrm{HC}$ interactions. Irrespective of the mechanism, the formation of $\mathrm{HC} \cdot \mathrm{HA}$ in arthritic joints enhances the binding of HA to its major cell surface receptor, CD44, on leukocytes (Zhuo et al., 2006), but it is unknown whether this, or indeed the altered hydrodynamic properties of the modified HA (Baranova et al., 2014), are part of a protective process or contributing to pathology (Day and Milner, 2019).

In some contexts, $\mathrm{HC} \cdot \mathrm{HAs}$ can be crosslinked by the binding of $\mathrm{HCs}$ to the octameric protein pentraxin-3 (PTX3) (Baranova et al., 2014), where, for example, the multivalent nature of PTX3 is essential to the stabilisation of the cumulus matrix (Inforzato et al., 2008). Either deletion of PTX3, or loss/impairment of TSG-6's HC transferase activity in mice, also leads to the failure of COC expansion and, hence, infertility (Briggs et al., 2015; Fülöp et al., 2003; Ochsner et al., 2003; Salustri et al., 2004). Here the cooperation between HA, I $\alpha$ I, PTX3 and TSG-6 (Baranova et al., 2014) leads to the formation of an elastic tissue, which is the softest described to date with a Young's modulus on the order of $1 \mathrm{~Pa}$ (Chen et al., 2016).

I $\alpha$ I has been implicated as a regulator of innate immunity having been shown to be an inhibitor of the complement system, affecting the alternative, classical and lectin activation pathways (Adair et al., 2009;

Garantziotis et al., 2007; Okroj et al., 2012). The inhibition of the alternative and classical pathways of complement is thought to be dependent on the HCs rather than bikunin (Garantziotis et al., 2007; Okroj et al., 2012); i.e. both $\mathrm{HC} 1$ and $\mathrm{HC} 2$, isolated from native I $\alpha \mathrm{I}$, had inhibitory activities in haemolytic assays (Okroj et al., 2012), however, the mechanism has not been determined. In the case of the alternative pathway, I $\alpha$ I was found to inhibit the enzymatic cleavage of factor $\mathrm{B}(\mathrm{FB})$ to $\mathrm{Bb}$, which occurs during the formation of the $\mathrm{C} 3$ convertase $(\mathrm{C} 3 \mathrm{bBb})$, and there is some evidence that $\mathrm{I} \alpha \mathrm{I}$ may interact with complement C3 (Garantziotis et al., 2007; Okroj et al., 2012).

I $\alpha$ I has also been found to bind to vitronectin (Adair et al., 2009), a multifunctional plasma and matrix protein that, as a well as being a regulator of complement system terminal pathway, also mediates binding to $\alpha_{V}$ integrins (Preissner and Reuning, 2011). Vitronectin's integrin-binding activity has an important role in epithelial repair in the context of lung homeostasis and the adhesion and migration of epithelial cells was promoted by its interaction with $\mathrm{I} \alpha \mathrm{I}$ (Adair et al., 2009); moreover, I $\alpha \mathrm{I}$-deficient mice had impaired recovery in experimental lung injury. The association between I $\alpha \mathrm{I}$ and vitronectin is reported to be of high affinity and inhibited by RGD peptides, implicating I I's vWFa domain in the interaction.

In order to explore and better explain the functions of HCs, we undertook structural and biophysical characterisation of the prototypical heavy chain, $\mathrm{HC} 1$. Here we present the crystal structure of $\mathrm{HC} 1$, and reveal that $\mathrm{HC} 1$ can form metal ion-dependent homodimers, which require a functional MIDAS motif within its $\mathrm{vWFa}$ domain. We also show that the MIDAS is important in HC1-mediated inhibition of the alternative pathway $\mathrm{C} 3$ convertase, via its interaction with $\mathrm{C} 3$, and demonstrate that $\mathrm{HC} 1$ can interact with vitronectin and other integrin ligands (e.g. small latent complexes of TGF $\beta$ ) in a MIDAS-independent manner. 


\section{Results}

\section{Structure of rHC1}

4 Our construct for recombinant $\mathrm{HC} 1(\mathrm{rHC} 1)$ encompasses the entire 638-residue mature protein sequence of human $\mathrm{HC} 1$ as defined by amino acid residues 35-672 in UniProt (ITH1, isoform A); see Supplementary Figure S1. Given that we observed weak metal ion-dependent dimerisation of $\mathrm{rHC} 1$ (see later), we conducted crystallisation screens using the D298A mutant that does not dimerise. Once crystals had been obtained with D298A, we were able to crystallise the wild type (WT) protein in similar conditions. The asymmetric unit of the crystals for both WT and D298A contained 2 independent copies of rHC1. Our crystal structure of rHC1 (at $2.34 \AA$ and $2.20 \AA$ resolution for WT (PDB: 6FPY) and D298A (PDB: 6FPZ), respectively; see Table 1) reveals that heavy chains are composed of 3 distinct domains (Figure 1). Its vWFa domain (residues 288477 ) is inserted into a loop in an integrin-like hybrid domain (termed here HC-Hybrid1) composed of residues 266-287 and 478-543 (and linked by a disulphide bond (Olsen et al., 1998)). These two domains sit atop a large, novel, 16-stranded $\beta$-sandwich, composed of residues 45-265 and 601-652, which we call the HC-Hybrid2 domain (Figure 1A). The C-terminal end of the HC-Hybrid1 domain is connected to the final loops of the HC-Hybrid2 domain by $3 \alpha$-helices (residues 544-600). A construct-derived hexa-His tag (AHHHHHHVGTGSNDDDDDKSP), and residues 35-44, 631-636 and 653-672 of HC1, clearly present in the protein preparation as determined by mass spectrometry, were not visible in the electron density and are therefore assumed to be unstructured or highly conformationally labile. This includes the native C-terminus of $\mathrm{HC} 1$, which is covalently attached to $\mathrm{CS}$ in I $\alpha \mathrm{I}$ and to $\mathrm{HA}$ in the context of $\mathrm{HC} \cdot \mathrm{HA}$ complexes. These missing residues were modelled using Small Angle X-ray Scattering (SAXS) data for (monomeric) D298A as a restraint target (Figure 1C,D); as can be seen, the AllosMod model fits better than the crystal structure alone to the experimental SAXS curve, with $\chi$ values of 1.56 and 2.68 , respectively.

Despite low sequence identities (17\% and $15 \%$, respectively), the $\mathrm{HC} 1 \mathrm{vWFa}$ domain is structurally most similar to the vWFa domains from capillary morphogenesis protein 2 (CMG2; Lacy et al., 2004) and tumour endothelial marker 8 (TEM8; Fu et al., 2010), with PDBeFold Q-scores of 0.56 and 0.52 respectively. These are both transmembrane proteins that serve as functional receptors for the anthrax toxin (Liu et al., 2012). $\mathrm{HC} 1$ also shows significant structural similarity to the vWFa domains of various integrin I-domains, with the highest Q-score (0.50) for integrin $\alpha_{M}$ (ITGAM; also known as CD11b and as complement receptor type 3 (CR3)), and the vWFa domain of complement factor B (FB; Q-score 0.37); FB and ITGAM are C3-binding proteins, with roles in complement activation/amplification and complement-mediated phagocytosis, respectively (Ricklin et al., 2016). From the structure of WT rHC1 it is apparent that its vWFa domain contains a metal ion-dependent adhesion site (MIDAS) motif (Figure 1B), which was predicted from its sequence (Rugg et al., 2005); residues Asp298, Ser300, Ser302 and Asp403 chelate a magnesium ion, the identity of which can be inferred from the trigonal bipyramid co-ordination geometry, bond distances and refined atomic displacement parameters (ADPs). The D298A mutant lacks the Asp298 sidechain and has no bound $\mathrm{Mg}^{2+}$ ion but is otherwise very similar to the WT structure, with a RMSD between the two most 
similar chains of $0.24 \AA ̊$ over $598 \mathrm{C}$-alpha atoms.

The HC-Hybrid1 domain of $\mathrm{HC} 1$ is composed of two 4-stranded $\beta$-sheets, where two of the $\beta$-strands are formed from amino acid residues before the $\mathrm{vWFa}$ domain and the remaining 6 from sequence after it; these regions are connected by a disulphide bond between Cys268 and Cys540. This arrangement of the HCHybrid1 and vWFa domains is reminiscent of integrin $\beta$-chains, as illustrated in Figure $2 \mathrm{~A}, \mathrm{~B}$ for a comparison of $\mathrm{rHC} 1$ with ITGB3. Here the topologies of the $\beta$-strands are similar and, when the vWFa domains of $\mathrm{HC} 1$ and ITGB3 are superimposed, the 'hybrid' domains are $\sim 40^{\circ}$ out of alignment (Figure 2C).

The HC-hybrid1 domain is a variant of the fibronectin type-III (FnIII) fold, and its closest structural match in mammalian extracellular proteins is the third FnIII domain from integrin IGTB4 (Alonso-García et al., 2015), with a RMSD between the structures of $1.55 \AA$. Curiously, the closest structural similarity overall is to the EAR domain of gamma 2 adaptin (RMSD - 1.28 $)$, a protein found in the clathrin adaptor complex, which is involved in intracellular protein transport and is hijacked in hepatitis B infection (Jürgens et al., 2013).

The HC1-Hybrid2 domain has a unique structure composed of $16 \beta$-strands arranged into two $\beta$-sheets. It is most similar to a "domain of unknown function" from PDB 4G2A, for which there is no accompanying publication. In the HC1-Hybrid2 domain one $\beta$-sheet is continuous, but the other has a missing strand, with a break in the hydrophobic core of the domain. The resulting subdomains are structurally homologous to immunoglobulin-like carbohydrate binding domains (residues 44-170) and a jelly-roll fold (residues 173263).

\section{rHC1 forms MIDAS and metal-ion dependent dimers}

During preparative size exclusion chromatography (SEC) of $\mathrm{rHC} 1$ for crystallisation the presence of a small amount of dimer was observed when we included metal ions in the buffer. Given that HC-HC interactions have been proposed to non-covalently cross-link HC•HA complexes (Yingsung et al., 2003), we explored this phenomenon further with both analytical ultracentrifugation (AUC) and SAXS. Velocity AUC revealed that in the presence of magnesium, WT $\mathrm{rHC1}$, while mostly monomeric, formed dimers (Figure 3A); here sedimentation coefficients $\left(\mathrm{s}_{(20, \mathrm{w})}\right)$ of $4.59 \mathrm{~S}$ and $6.11 \mathrm{~S}$ were obtained. Equilibrium AUC conducted at a range of magnesium ion concentrations (Supplementary Figure S2) showed that this interaction was indeed $\mathrm{Mg}^{2+}$ dependent, although the affinity is rather weak $\left(K_{\mathrm{D}}=35.3 \mu \mathrm{M}\right.$ at $1 \mathrm{mM} \mathrm{MgCl}$; Figure $\left.3 \mathrm{~B}\right)$. We used high-throughput SAXS screening, generating $\mathrm{D}_{\max }$ (maximum dimension) values, as an efficient way of determining dimerisation in a range of different metal ion conditions (Table 2). Magnesium chloride and manganese chloride supported dimerisation, whereas calcium chloride and EDTA did not. D298A did not form $\mathrm{Mg}^{2+}$ - or $\mathrm{Mn}^{2+}$-dependent dimers and, therefore, we concluded that the dimerisation activity of $\mathrm{rHC} 1$ requires a correctly formed and metal ion-occupied MIDAS that can accommodate either a magnesium or manganese ion. 
SAXS data for the rHC1 monomer (D298A in $\mathrm{MgCl}_{2}$ ) and dimer (wild type in $\mathrm{MgCl}_{2}$ ) were used to obtain low resolution $a b$ initio solution structures (Figure 3C-E); see Supplementary Figure S3 for analysis of SAXS data, showing the rHC1 monomer and dimers to be folded and rigid. For the monomer it was apparent that the crystal structure for $\mathrm{rHC} 1$ could be well accommodated within the SAXS envelope. On the other hand, when two $\mathrm{HC} 1$ molecules were fitted into the envelope for the $\mathrm{rHC} 1$ dimer the fitting was ambiguous; the model presented in Figure 3C gives the best overall fit-to-map correlation, but other models give similar scores. One likely explanation is that a conformational change occurs in the $\mathrm{HC} 1$ structure on dimerisation. Moreover, small differences between the sedimentation coefficients determined by velocity AUC for the monomer species in EDTA (4.39 S) and $\mathrm{MgCl}_{2},(4.59 \mathrm{~S})$ indicate that metal ion binding induces a structural change in the monomeric protein prior to dimer formation; i.e. consistent with a recent biochemical analysis (Scavenius et al., 2016). However, while this change is evident in the solution phase, we saw no such difference between the crystal structures for WT HC1 with a bound $\mathrm{Mg}^{2+}$ ion and the metal ion-free D298A mutant. This could be due to the fact that the initial crystallisation conditions were obtained from D298A protein, and that these conditions stabilise the protein in a monomeric configuration. The potential dimers observed in the crystal lattice do not correlate with the SAXS data.

\section{rHC1 structure enables modelling of inter-alpha-inhibitor}

18 We recorded SAXS data for I $\alpha \mathrm{I}$ purified from human plasma and found that even in the presence of $5 \mathrm{mM}$ $\mathrm{MgCl}_{2}$ it is monomeric (Figure 4A, B and Supplementary Figure S4); I $\alpha$, which is likely rigid, has an elongated shape (Figure $4 \mathrm{C}$ ), with a $\mathrm{D}_{\max }$ value of $17.0 \mathrm{~nm}$, which is similar to that for the $\mathrm{HC} 1$ dimer (Figure $3 \mathrm{C}$, Table 2). The SAXS data (collected in HEPES buffered saline with $2 \mathrm{mM} \mathrm{MgCl}_{2}$ ) were used to generate an $a b$ initio solution structure for $\mathrm{I} \alpha \mathrm{I}$ and thereby determine the likely quaternary organisation of the $\mathrm{I} \alpha \mathrm{I}$ complex (Figure 4C), i.e. using the structures of bikunin (Xu et al., 1998) and rHC1, and a homology model of $\mathrm{HC} 2$ based on the $\mathrm{HC} 1$ coordinates (determined here) and experimentally determined disulphide bonds (Olsen et al., 1998). The three protein chains of I $\alpha$ I could be readily fitted within the SAXS envelop with the bikunin chain being accommodated in a small lobe at one end and the two HCs arranged asymmetrically in the larger lobe; this positioning would place the C-terminal peptides of $\mathrm{HC} 1$ and $\mathrm{HC} 2$ on the same face, making them close enough to take part in the observed CS conjugation. The I $\mathrm{I}$ model shown in Figure 4C was used to back calculate SAXS data, where this was found to have reasonable agreement with the

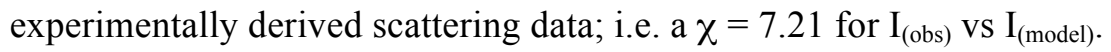

\section{rHC1 inhibits the alternative complement pathway in a MIDAS-dependent manner}

Given there is evidence that $\mathrm{I} \alpha \mathrm{I}$ binds to $\mathrm{C} 3$ and that heavy chains are inhibitors of the alternative and classical complement pathways (Okroj et al., 2012), we investigated whether rHC1 could interact with C3 (i.e. the central component of complement). Initial buffer screening using surface plasmon resonance (SPR), revealed that $\mathrm{rHC} 1$ interacted with $\mathrm{C} 3$ in a $\mathrm{Mn}^{2+}$-ion-dependent manner, which is mediated via the $\mathrm{HC} 1$ MIDAS motif since the D298A mutant exhibited no binding activity (Figure 5A; Table 3); there was also an interaction in $\mathrm{Mg}^{2+}$ (albeit of lower apparent affinity) but there was no binding in the presence of $\mathrm{Ca}^{2+}$ or 
EDTA (data not shown). Full SPR analysis (in $2 \mathrm{mM} \mathrm{MgCl}_{2} / 2 \mathrm{mM} \mathrm{MnCl}_{2}$ ) determined that the $K_{D}$ for the rHC1-C3 interaction was $\sim 360 \mathrm{nM}$, i.e. a similar affinity to the binding of $\mathrm{C} 3$ to $\mathrm{I} \alpha \mathrm{I}\left(K_{\mathrm{D}}=\sim 660 \mathrm{nM}\right.$; Table 3). When we tested $\mathrm{rHC1}$ in a functional assay of complement activation we found that the WT protein, but not the D298A mutant (data not shown), was able to dose-dependently inhibit the activity of the alternative pathway $\mathrm{C} 3$ convertase $(\mathrm{C} 3 \mathrm{bBb})$ with an $\mathrm{IC}_{50}$ of $980 \mathrm{nM}$ (Figure $5 \mathrm{~B}$ ).

The divalent cation and MIDAS-dependent interaction of $\mathrm{rHC} 1$ with $\mathrm{C} 3$ is reminiscent of the manner in which $\mathrm{FB}$ associates with $\mathrm{C} 3 \mathrm{~b}$ (activated $\mathrm{C} 3$ ) to form the $\mathrm{C} 3$ convertase; this is mediated by the $\mathrm{vWFa}$ domain in $\mathrm{FB}$ binding to the $\mathrm{C}$-terminus of $\mathrm{C} 3 / \mathrm{C} 3 \mathrm{~b}$ via co-chelation of a $\mathrm{Mg}^{2+}$ ion bound to FB's MIDAS motif (Forneris et al., 2010). In sillico modelling of the $\mathrm{HC} 1 \mathrm{vWFa}$ and the C-terminal domain (C345C) of $\mathrm{C} 3 / \mathrm{C} 3 \mathrm{~b}$ (Figure 5C) reveals that a MIDAS-mediated interaction is indeed feasible and consistent with a low resolution SAXS structure determined for the rHC1-C3 complex (Figure 5D and Supplementary Figure S5); while the complex is folded and globular, Porod-Debye analysis indicated that it had some flexibility.

\section{HC1 binds to integrin ligands in a MIDAS-and vWFa-independent manner}

Given the structural similarity of $\mathrm{HC} 1$ to integrin $\beta$-subunits and our finding that $\mathrm{rHC} 1$ dimerises and binds to complement $\mathrm{C} 3$ in a metal ion-, and likely MIDAS motif-, dependent manner we wanted to further explore its interaction with integrin ligands; as described above, I $\alpha \mathrm{I}$ is known to bind to vitronectin, where the vWFa domain has been implicated in binding (Adair et al., 2009). Our SPR analysis (Supplementary Figure S6) showed that $\mathrm{rHC} 1$ binds with high affinity to vitronectin, however, to our surprise this was independent of metal ions (Table 3); essentially identical shaped binding curves were seen for experiments in $\mathrm{Mg}^{2+} / \mathrm{Mn}^{2+}$ and EDTA (data not shown). Moreover, the D298A mutant and a construct where the vWFa domain had been removed $(\Delta \mathrm{vWFa})$ both bound to vitronectin with very similar affinities to the WT protein (Supplementary Figure S6C; Table 3).

We also investigated the binding of rHC1 to the small-latent complexes (SLC) of TGF $\beta 1,2$, and 3, in which the growth factors are coupled to latency-associated peptides (LAP); TGF $\beta 1$-LAP and TGF $\beta 3$-LAP (which both contain an RGD motif) are activated by the $\alpha_{V} \beta_{6}$ and $\alpha_{V} \beta_{8}$ integrins, in response to mechanical stress, in a metal ion- and MIDAS-dependent manner (Annes et al., 2004; Shi et al., 2011; Worthington et al., 2015). As shown in Supplementary Figure S6D, we found that rHC1 could interact tightly with TGF $\beta 1$-LAP, TGF $\beta 2$-LAP and TGF $\beta 3$-LAP, where the affinity $\left(K_{\mathrm{D}} \sim 10 \mathrm{nM}\right)$ was essentially identical for the WT and D298A mutant (Table 3); moreover, similar binding was seen in EDTA (not shown). Together this demonstrates that the interactions are independent of metal ions and do not involve HC1's MIDAS motif. Additional SPR experiments revealed that $\mathrm{rHC} 1$ interacts with the LAP peptide (analysed for the LAP from TGF $\beta 1 ; K_{D}=2 \mathrm{nM}$ ) but did not bind to the mature growth factor (i.e. TGF $\beta 1$ and TGF $\beta 3$ ). SLCs associate with latent TGF $\beta$ binding proteins (LTBP) to form large latent complexes (LLCs) (Robertson et al., 2015); this mediates matrix sequestration and regulates the activation of latent TGF $\beta$. We tested whether rHC1 
bioRxiv preprint doi: https://doi.org/10.1101/695700; this version posted July 8, 2019. The copyright holder for this preprint (which was not certified by peer review) is the author/funder, who has granted bioRxiv a license to display the preprint in perpetuity. It is made available under aCC-BY-NC-ND 4.0 International license.

1 could bind to LTBP1 and found that it interacts with the N-terminal region (NT1), again in a metal ion2 independent manner, but not with the C-terminal (CT) or EGF regions (Table 3). 


\section{Discussion}

Here we have determined the first crystal structure for a heavy chain of the I $\mathrm{I} / \mathrm{ITIH}$ family. Given the similarity of the prototypical $\mathrm{HC} 1$ to the 5 other $\mathrm{HC}$ proteins encoded in the human genome $32-54 \%$ sequence identity), our study defines the canonical structure for a heavy chain, allowing the modelling of other family members. In this regard, we generated a homology model of HC2 that, along with the structure for $\mathrm{rHC} 1$ (and bikunin), allowed us to infer the quaternary organisation of I $\alpha \mathrm{I}$ itself. Our SAXS-based modelling of I $\alpha$ I (Figure 4) reveals that this unusual CS proteoglycan forms an elongated structure, but with a compact arrangement of the 3 protein chains as also inferred in a recent study (Scavenius et al., 2016).

Unlike I $\alpha$ I, which is monomeric, $\mathrm{rHC} 1$ forms a dimer in solution. Given the metal ion-dependence of dimer formation (requiring $\mathrm{Mg}^{2+}$ or $\mathrm{Mn}^{2+}$; Table 2) and the lack of dimerisation by the D298A mutant, the MIDAS motif within the vWFa domain clearly plays an essential role in mediating this protein-protein interaction. It is possible that an Asp or Glu sidechain on one $\mathrm{HC} 1$ monomer could engage with the metal ion within the MIDAS of the other $\mathrm{HC1}$; e.g. to effect a conformational change, thereby altering the orientation of the vWFa domain relative to the rest of the protein and leading to the dimer dimensions indicated by SAXS (Figure 3C). This is reminiscent of how metal ion and ligand occupancy of an integrin MIDAS can transduce a conformational change that causes the hybrid and vWFA domains to swing away from one another during integrin activation (Luo et al., 2007; Wang et al., 2017). The arrangement of the HC1 and HC2 vWFa domains in our I $\alpha \mathrm{I}$ model (Figure 4C) indicate that such interactions would be sterically precluded, explaining why $\mathrm{I} \alpha \mathrm{I}$ does not dimerise.

It is well established that $\mathrm{HC} 1, \mathrm{HC} 2$ and $\mathrm{HC} 3$ can become covalently attached to the polysaccharide $\mathrm{HA}$, via transesterification reactions catalysed by TSG-6, e.g. in the context of ovulation and inflammation; see (Day and Milner, 2019). This reaction requires the presence of $\mathrm{Ca}^{2+}$ and $\mathrm{Mg}^{2+} / \mathrm{Mn}^{2+}$ ions (Briggs et al., 2015) and occurs via the formation of covalent TSG-6•HC intermediates (Rugg et al., 2005). There is a $\mathrm{Ca}^{2+}$ ionbinding site in TSG-6, which we have shown previously to be essential for TSG-6•HC formation (Briggs et al., 2015), and our finding here that a $\mathrm{Mg}^{2+}$ or $\mathrm{Mn}^{2+}$ ion can be accommodated within the vWFa domain of $\mathrm{HC} 1$ (Figure 1) provides strong evidence that HCs are the source of these metal ions. Moreover, solving the heavy chain structure will facilitate refinements in our understanding of the mechanisms underlying the transfer of HCs onto HA.

The dimerization of $\mathrm{rHCl}$ provides the first direct evidence that homotypic $\mathrm{HC}-\mathrm{HC}$ interactions might contribute to the stabilisation of HC•HA-rich matrices. Given that the C-terminal 19 amino acid residues of $\mathrm{HC} 1$ (which were not visible in the crystal structure) are likely to form a flexible linker, this protein-protein interaction is unlikely to be affected by whether the C-terminus of $\mathrm{HC} 1$ is covalently attached to HA or not. We found that the $\mathrm{HC} 1-\mathrm{HC} 1$ interaction is rather weak $\left(K_{\mathrm{d}} \sim 40 \mu \mathrm{M}\right.$ at physiological $\mathrm{Mg}^{2+}$ concentrations; Figure 3B) indicating that, for this heavy chain, at least, binding is likely to be highly transient. As yet we do not know whether other HCs self-associate in this way or indeed the nature/affinities of heterotypic HC-HC 
interactions. However, it seems reasonable to propose that low affinity binding between HCs could mediate the aggregation of $\mathrm{HC} \cdot \mathrm{HAs}$ seen in synovial fluids from rheumatoid arthritis patients (Yingsung et al., 2003) and that this, combined with more stable interactions between HCs and PTX3 (Baranova et al., 2014), underpin the formation and crosslinking of the cumulus extracellular matrix during COC expansion. Furthermore, dynamic HC-HC interactions could make an important contribution to the mechanical properties of tissues; for example, they might explain the elasticity and extreme softest of the cumulus matrix (Chen et al., 2016). Certainly $\mathrm{HC} \cdot \mathrm{HAs}$ have different compositions of heavy chains in different tissue contexts (Day and Milner, 2019) and it seems likely that this will engender distinct hydrodynamic and functional properties.

We found that $\mathrm{rHC} 1$ was able to bind to complement $\mathrm{C} 3$ with moderate affinity $\left(K_{\mathrm{D}} \sim 360 \mathrm{nM}\right.$; Table 3 ), thereby identifying this complement component as a novel heavy chain ligand. Modelling of the rHC1-C3 complex (Figure 5) demonstrated that this interaction could be mediated via the $\mathrm{C}$-terminus of $\mathrm{C} 3$ cochelating the metal ion within the MIDAS of $\mathrm{HC} 1$. This also provides a plausible mechanism by which $\mathrm{rHC} 1$ (and potentially $\mathrm{I} \alpha \mathrm{I}$ ) inhibits the activity of the alternative pathway $\mathrm{C} 3$ convertase (Figure 5C), by acting as a competitor of the interaction between FB and C3. Displacement of FB may also explain how I $\alpha$ I inhibits the factor D-mediated cleavage of FB to $\mathrm{Bb}$ (Okroj et al., 2012), as this reaction requires FB to be associated with $\mathrm{C} 3$. In our functional assays, $\mathrm{rHC} 1$ was an approximately 10 -fold weaker inhibitor compared to human factor $\mathrm{H}(\mathrm{FH})$, the only established negative regulator of the alternative pathway in the solution-phase (see (Parente et al., 2017)). While I $\alpha \mathrm{I}$ and FH have similar concentrations in serum, in tissues where HC1 accumulates via covalent attachment to HA, its complement inhibitory activity could serve to dampen the innate immune response. HC1-mediated inhibition of complement activation might be particularly important during ovulation, where plasma proteins (including complement components and I $\alpha$ I) ingress into the ovarian follicle when the blood-follicle barrier breaks down, i.e. to provide protection to the COC prior to ovulation.

Our discovery that the vWFA of HC1 shares high structural similarity with those of TEM8 and CMG2 may be significant given that these proteins are known to be functional receptors for the anthrax toxin (Liu et al., 2012) and because I $\alpha$ I has been shown to protect against anthrax intoxication (Opal et al., 2011; Singh et al., 2010). The latter has previously been attributed to the activity of the bikunin chain in inhibiting furins/preprotein convertases, which are proteases that have a critical role in the assembly of the anthrax toxin protective antigen (Opal et al., 2005). The protective antigen binds to the host cell surface by utilising the receptors CMG2 and TEM8 (Liu et al., 2012), both of which contain vWFA domains that mediate the interaction via their MIDAS motifs (Fu et al., 2010; Lacy et al., 2004), in a similar manner to how integrins interact with their ligands. Thus, our data are consistent with a mechanism whereby I $\alpha \mathrm{I}$ and HCs act as decoy receptors for the anthrax toxin and sequester the toxin in the fluid phase, preventing it from binding to membranes and forming the pores that give rise to the toxin's cytotoxic activity. 
1 We have identified that $\mathrm{rHC} 1$ binds to vitronectin (a ligand of the $\alpha_{\mathrm{V}} \beta_{6}$ integrin) with very high affinity $\left(K_{\mathrm{D}}\right.$ $\sim 0.2 \mathrm{nM}$; Table 3), consistent with a previous report (Adair et al., 2009). However, our data clearly demonstrate for $\mathrm{HC} 1$ (at least) that the interaction with vitronectin does not involve the vWFa domain and is thus not a typical RGD-mediated MIDAS co-chelation interaction; e.g. an $\mathrm{rHC} 1$ construct lacking the entire vWFa domain bound to vitronectin with similar affinity to the wildtype protein (Supplementary Figure S6C; Table 3). The finding that the binding of I $\alpha$ I to vitronectin is inhibited by RGD peptides (Adair et al., 2009) is intriguing and suggests that even though this interaction is not mediated by metal ions the integrin-binding site in vitronectin may be involved. Further work is needed to investigate this possibility and determine the effect of $\mathrm{HC} 1$ on $\alpha_{\mathrm{V}} \beta_{6}$-vitronectin interactions.

In light of the tight but non-canonical interaction of $\mathrm{rHC} 1$ with vitronectin, and given that TGF $\beta 1$ and TGF $\beta 3$ interact with $\alpha_{V} \beta_{6}$ via RGD sequences within their latency-associated peptides (Annes et al., 2004; Shi et al., 2011), we screened the 3 small latent complexes of TGF $\beta$, for binding to $\mathrm{rHC}$. We found that all three SLCs interacted with $\mathrm{rHC1}$ with high affinity $\left(K_{\mathrm{D}} \sim 10 \mathrm{nM}\right.$; Table 3$)$, including TGF $\beta 2$-LAP that doesn't have an RGD motif. As in the case of vitronectin, the D298A mutant of rHC1 (with a defective MIDAS) bound the SLCs with similar affinities to WT rHC1. Additional SPR data indicated that rHC1 binds to the LAP rather than the mature growth factors and also interacts with the N-terminal region of LTBP1, which associates with TGF $\beta$-LAP to form the large latent complex (LLC). Given that the LLCs sequester TGF $\beta$ s in the matrix (Robertson et al., 2015), through interactions with both the $\mathrm{N}$ - and C-terminal regions of LTBP1, it seems reasonable to suggest that $\mathrm{HC} 1$ may play a role in regulating the bioavailability of these important growth factors/cytokines. In this regard, whether $\mathrm{HC} 1$ acts in an analogous fashion to $\alpha_{\mathrm{V}} \beta 6$, i.e. to mechanically activate the release of mature TGF $\beta$ (Buscemi et al., 2011), or whether it stabilises the LLC remains to be determined. The latter seems more likely based on its binding to both LAP and LTBP1 and is consistent with the finding that $\mathrm{HC} \cdot \mathrm{HA}$ complexes present in the human amniotic membrane, which are reported to only contain $\mathrm{HC1}$ (Zhang et al., 2012), have been found to be potently tissue protective with antifibrotic activity (Ogawa et al., 2017).

In summary, this study has identified that $\mathrm{HC} 1$ has a structural organisation reminiscent of an integrin $\beta$ chain, including $\mathrm{vWFa} /$ hybrid domains and a functional MIDAS motif that mediates some but not all of its ligand-binding interactions. Our novel findings that $\mathrm{HC} 1 \mathrm{can}$ inhibit the complement system and has the potential to modulate TGF $\beta$ activity indicates that this protein is likely to be an important regulator of the innate and adaptive immune systems, for example, when it becomes covalently associated in the extracellular matrix during inflammation. 


\section{Materials and Methods}

\section{Protein production}

The rHC1 proteins (WT, D298A and a $\Delta \mathrm{vWFa}$ mutant, lacking residues 288-478) and the recombinant domains of LTBP1 (NT1, EGF and CT) were expressed and purified as described previously (Baranova et al., 2013; Troilo et al., 2016). LAP (from TGF $\beta 1$ ), TGF $\beta 1$, TGF $\beta 1$-LAP, TGF $\beta 2$-LAP, TGF $\beta 3$ and TGF $\beta 3$ LAP were obtained from R\&D Systems, vitronectin was from PeproTech and complement C3 from Merck. I $\alpha$ I was purified from human plasma as described previously (Enghild et al., 1989).

\section{Crystallography of rHC1}

11 WT $\mathrm{rHC} 1$ and the D298A mutant were crystallised by mixing $1 \mu \mathrm{l}$ of protein $(10 \mathrm{mg} / \mathrm{ml}$ in $10 \mathrm{mM}$ HEPES $\mathrm{pH}$ $7.5,50 \mathrm{mM} \mathrm{NaCl})$ with an equal amount of crystallisation mother liquor (100mM HEPES, pH 7.5, 100mM sodium acetate, 10\% (w/v) PEG8K, 20\% (v/v) glycerol). Crystals appeared within one week. Native diffraction data were collected to $2.20 \AA$ (D298A) and $2.34 \AA$ (WT) and the data were indexed, integrated and scaled using DIALS (Waterman et al., 2016), POINTLESS (Evans, 2011), AIMLESS/SCALA (Evans et al., 2006; Evans et al., 2013) and cTRUNCATE (Evans, 2011) as implemented in the Xia2 pipeline (Winter et al., 2013). The data were phased using the SIRAS method and a $\mathrm{K}_{2} \mathrm{PtCl}_{4}$-derivatised D298A crystal. The substructure was solved, and the data phased, density modified and the chain partially traced using PHENIX AutoSol (Terwilliger et al., 2009). Both the WT and D298A models were rebuilt and refined to convergence using the COOT (Emsley et al., 2010) and PHENIX Refine (Afonine et al., 2012) packages. Data collection statistics are shown in Table 1. The refined models have been deposited in the PDB databank with accession codes 6FPY (WT) and 6PFZ (D298A).

\section{Small angle X-ray scattering and modelling of I $\alpha I$, rHC1 and rHC1-C3 complex}

SAXS data were collected at beamline P12, PetraIII, DESY (Blanchet et al., 2015). Proteins (rHC1 or I $\alpha$ I) at $1.25,2.5$ and $5.0 \mathrm{mg} / \mathrm{ml}$ were prepared in HEPES buffered saline $(\mathrm{pH} \mathrm{7.5).} \mathrm{Data} \mathrm{were} \mathrm{reduced} \mathrm{using}$ PRIMUS/GNOM (Konarev et al., 2003; Svergun, 1992). The $R_{g}$ and $D_{\max }$ values shown in Table 2 were calculated automatically using AUTORG and DATGNOM (Petoukhov et al., 2007) to prevent bias or subjective interpretation. Ab initio models were created using the DAMMIF/DAMMIN packages (Franke and Svergun, 2009; Svergun, 1999); 20 models were made using DAMMIF in slow mode. The averaged model from DAMMIF was refined to convergence using DAMMIN. Modelling of residues missing from the crystal structure was done using the Allosmod-FoXs server (Weinkam et al., 2012). Modelling of the dimeric form of $\mathrm{HC} 1$ was carried out as for the monomeric form, although P2 symmetry was enforced once it was determined that the data corresponded to a dimer. Rigid body docking of the $\mathrm{HC} 1$ structure into the resulting DAMMIN envelope was performed in UCSF Chimera for both monomeric and dimeric HC1. The resolution of the resulting map used for fitting was determined using SASRES (Tuukkanen et al., 2016); this was $43 \AA$ for the monomer and $64 \AA$ for the dimer. In modelling of the dimer, we enforced the two-fold axis from the 
et al., 2015) and modelled along with bikunin (Xu et al., 1998) and HC1 into the DAMMIN envelope using Sculptor (Wahle and Wriggers, 2015) simultaneous docking protocols.

Structures of the rHC1 vWFa domain (this study) and the complement C3 C-terminal C345C domain (PDB 2XWJ (Forneris et al., 2010)) were positioned relative to each other informed by the C3-FB complex (2XWJ). The models were locally docked to each other using Rosetta_3.2 and the standard docking protocol (Leaver-Fay et al., 2011), with random perturbations of $3 \AA$ and $8^{\circ} ; 10,000$ models were generated and the lowest energy model is shown in Figure 5D. Additionally, a SAXS envelope was generated of full length C3 bound to $\mathrm{rHCl}$ in the presence of $2 \mathrm{mM} \mathrm{MnCl}_{2}$. DAMMIN envelopes were calculated as described above. Crystal structures of C3 (PDB 2A73 (Janssen et al., 2005)) and HC1 (this study) were docked into this envelope using Sculptor (Wahle and Wriggers, 2015).

\section{Analytical ultracentrifugation of rHC1}

The metal ion dependence of $\mathrm{rHC} 1$ dimerisation was analysed using both velocity and equilibrium AUC. All AUC experiments were conducted at $20^{\circ} \mathrm{C}$ on a Beckman XL-A ultracentrifuge with an An60Ti rotor. For velocity AUC, $18 \mu \mathrm{M}$ WT $\mathrm{rHC} 1$ protein was prepared in HEPES buffered saline $\mathrm{pH} 7.5$, either in the presence of $2.5 \mathrm{mM}$ EDTA or $5 \mathrm{mM} \mathrm{MgCl}_{2}$. The samples were analysed at $40,000 \mathrm{rpm}$ for $5 \mathrm{~h}$, with scans taken at $280 \mathrm{~nm}$ every $90 \mathrm{~s}$. This experiment was conducted in triplicate with representative data shown in Figure 3A. Sedimentation coefficient distributions (c(s)) were calculated using SEDFIT (Schuck, 2000).

For equilibrium AUC, measurements were made at 3 different concentrations of $\mathrm{rHC} 1(4,11$, and $22 \mu \mathrm{M})$, where these were each prepared with 5 different concentration of $\mathrm{MgCl}_{2}(0$ (2.5 mM EDTA), 0.1, $0.5,1$ and $5 \mathrm{mM}$ ). Rotor speeds of 10,000,15,000, and 20,000 rpm were used with scans at $280 \mathrm{~nm}$ (and 290nm for the highest concentration) after equilibrium had been reached $(18 \mathrm{~h})$. Data (from triplicate experiments) were analysed by global analysis with SEDFIT/SEDFAT (Houtman et al., 2007) and fitted to a monomer-dimer model.

\section{Surface plasmon resonance of rHC1-ligand interactions}

SPR experiments were conducted on either a Biacore 3000 or T200 instrument. For C3 binding assays, 2,000 RU of C3 was immobilised on a CM5 chip using standard amide coupling chemistry and rHC1 was injected at a range of concentrations $(1 \mu \mathrm{M}-31.25 \mu \mathrm{M})$ over the chip surface. For all other assays, $\sim 1,500$ $\mathrm{RU}$ of $\mathrm{rHC} 1$ proteins (WT, D298A or $\Delta \mathrm{vWFa}$ ) were immobilised on a $\mathrm{C} 1$ chip by amide cross-linking chemistry and LAP (from TGF $\beta 1 ; 3.125 \mathrm{nM}-200 \mathrm{nM}$ ), LTBP1 (NT1, EGF or CT domains; all at 0.156nM 10nM), TGF $\beta 1$, TGF $\beta 3$ (both at 7.8nM - 500nM), TGF $\beta 1$-LAP, TGF $\beta 2$-LAP, TGF $\beta 3$-LAP (all at 3.125nM $-200 \mathrm{nM})$ or vitronectin $(0.3125 \mathrm{nM}-10 \mathrm{nM})$ were used as the analyte. Experiments were conducted in HEPES buffered saline, pH 7.5 with $0.05 \%(\mathrm{v} / \mathrm{v})$ Tween-20. Metal ions $(2 \mathrm{mM})$ or chelating agent (EDTA; $10 \mathrm{mM}$ ) were added to the buffers and a flow rate of $50 \mu \mathrm{l} / \mathrm{min}$ was used when generating kinetic parameters. Data were collected in triplicate and $K_{\mathrm{D}}$ values (mean \pm S.D. in Table 3) were determined from multicycle kinetics, where data were fitted to a Langmuir 1:1 model using the BIAeval T200 software. For all fits, the 
$1 \quad$ Chi $^{2}$ value obtained was less than $10 \%$ of the $\mathrm{R}_{\max }$ value.

\section{C3 convertase assay}

Inhibition of $\mathrm{C} 3$ activation to $\mathrm{C} 3 \mathrm{~b}$ was measured using a fluid phase convertase assay. Here C3 $(19.5 \mu \mathrm{M})$ was incubated with $1.75 \mu \mathrm{M}$ complement factor B (FB) and $0.37 \mu \mathrm{M}$ complement factor D in 20mM HEPES, $130 \mathrm{mM} \mathrm{NaCl}, 3 \mathrm{mM} \mathrm{MgCl} 2,1 \mathrm{mM}$ EGTA, $\mathrm{pH}$ 7.5. The effect of $\mathrm{rHC} 1$ (preincubated with $1 \mathrm{mM} \mathrm{MnCl}_{2}$ ) was measured at concentrations ranging from 0 to $27 \mu \mathrm{M}$; complement factor $\mathrm{H}(\mathrm{FH})$ was used as a positive control. After 1-min incubation at $37^{\circ} \mathrm{C}$, the reaction was stopped by addition of 5x SDS loading buffer and samples were incubated at $100^{\circ} \mathrm{C}$ for $5 \mathrm{~min}$. The samples were run on a $4-12 \%$ gradient SDS-PAGE gel and stained with Coomassie Blue. C3a formation was monitored by densitometry using an Odyssey imaging system (LI-COR Biosciences).

\section{Author Contributions (CRediT Compliant)}

Conceptualization D.C.B. and A.J.D.; Methodology D.C.B., A.W.L-S. and T.A.J.; Formal analysis D.C.B.; Investigation D.C.B. and A.W.L-S.; Resources A.J.D., C.B., D.C.B., J.J.E., C.M.K., C.M.M.; Data curation D.C.B.; Writing - Original Draft D.C.B. and A.J.D.; Writing - Review \& Editing all authors; Visualisation D.C.B.; Supervision A.J.D. and C.M.M.; Funding acquisition A.J.D. and C.M.M.

\section{Acknowledgements}

We gratefully acknowledge funding from Arthritis Research UK (19489) and the Medical Research Council (K004441). We would also like to thank Ruth Steer and Helen Troilo for making the LTBP1 domains and the beamline scientists at Diamond (UK) and DESY PETRA III (Germany) where we collected crystallography (beamline IO3) and SAXS data (beamlines I22 and EMBL-P12). Other biophysical analyses were carried out in the BioMolecular Analysis Core Facility at the University of Manchester, which is supported by Centre funding from the Wellcome Trust (088785/Z/09/Z and 203128/Z/16/Z).

\section{Competing interests}

None of the authors have any financial or non-financial competing interests associated with the work described in this paper. 


\section{References}

Adair, J.E., Stober, V., Sobhany, M., Zhuo, L., Roberts, J.D., Negishi, M., Kimata, K., and Garantziotis, S. (2009). Inter- $\alpha$-trypsin inhibitor promotes bronchial epithelial repair after injury through vitronectin binding. J. Biol. Chem. 284, 16922-16930.

Afonine, P. V., Grosse-Kunstleve, R.W., Echols, N., Headd, J.J., Moriarty, N.W., Mustyakimov, M., Terwilliger, T.C., Urzhumtsev, A., Zwart, P.H., Adams, P.D., et al. (2012). Towards automated crystallographic structure refinement with phenix.refine. Acta Crystallogr. Sect. D Biol. Crystallogr. 68, 352-367.

Alonso-García, N., García-Rubio, I., Manso, J.A., Buey, R.M., Urien, H., Sonnenberg, A., Jeschke, G., and de Pereda, J.M. (2015). Combination of X-ray crystallography, SAXS and DEER to obtain the structure of the FnIII-3,4 domains of integrin $\alpha 6 \beta 4$. Acta Crystallogr. Sect. D Biol. Crystallogr. 71, 969-985. Annes, J.P., Chen, Y., Munger, J.S., and Rifkin, D.B. (2004). Integrin alphaVbeta6-mediated activation of latent TGF-beta requires the latent TGF-beta binding protein-1. J. Cell Biol. 165, 723-734. Baranova, N.S., Foulcer, S.J., Briggs, D.C., Tilakaratna, V., Enghild, J.J., Milner, C.M., Day, A.J., and Richter, R.P. (2013). Inter- $\alpha$-inhibitor impairs TSG-6-induced hyaluronan cross-linking. J. Biol. Chem. 288, 29642-29653.

Baranova, N.S., Inforzato, A., Briggs, D.C., Tilakaratna, V., Enghild, J.J., Thakar, D., Milner, C.M., Day, A.J., and Richter, R.P. (2014). Incorporation of pentraxin 3 into hyaluronan matrices is tightly regulated and promotes matrix cross-linking. J. Biol. Chem. 289, 30481-30498.

Blanchet, C.E., Spilotros, A., Schwemmer, F., Graewert, M.A., Kikhney, A., Jeffries, C.M., Franke, D., Mark, D., Zengerle, R., Cipriani, F., et al. (2015). Versatile sample environments and automation for biological solution X-ray scattering experiments at the P12 beamline (PETRA III, DESY). J. Appl. Crystallogr. 48, 431-443.

Briggs, D.C., Birchenough, H.L., Ali, T., Rugg, M.S., Waltho, J.P., Ievoli, E., Jowitt, T.A., Enghild, J.J., Richter, R.P., Salustri, A., et al. (2015). Metal ion-dependent heavy chain transfer activity of TSG-6 mediates assembly of the cumulus-oocyte matrix. J. Biol. Chem. 290, 28708-28723.

Buscemi, L., Ramonet, D., Klingberg, F., Formey, A., Smith-Clerc, J., Meister, J.-J., and Hinz, B. (2011). The single-molecule mechanics of the latent TGF- $\beta 1$ complex. Curr. Biol. 21, 2046-2054.

Chen, X., Bonfiglio, R., Banerji, S., Jackson, D.G., Salustri, A., and Richter, R.P. (2016). Micromechanical analysis of the hyaluronan-rich matrix surrounding the oocyte reveals a uniquely soft and elastic composition. Biophys. J. 110, 2779-2789.

Day, A.J., and Milner, C.M. (2019). TSG-6: A multifunctional protein with anti-inflammatory and tissueprotective properties. Matrix Biol. 78-79, 60-83.

Emsley, P., Lohkamp, B., Scott, W.G., and Cowtan, K. (2010). Features and development of Coot. Acta Crystallogr. Sect. D Biol. Crystallogr. 66, 486-501.

Enghild, J.J., Thøgersen, I.B., Pizzo, S. V, and Salvesen, G. (1989). Analysis of inter-alpha-trypsin inhibitor and a novel trypsin inhibitor, pre-alpha-trypsin inhibitor, from human plasma. Polypeptide chain stoichiometry and assembly by glycan. J. Biol. Chem. 264, 15975-15981. 
Enghild, J.J., Salvesen, G., Hefta, S.A., Thøgersen, I.B., Rutherfurd, S., and Pizzo, S. V (1991). Chondroitin 4-sulfate covalently cross-links the chains of the human blood protein pre-alpha-inhibitor. J. Biol. Chem. $266,747-751$.

Enghild, J.J., Salvesen, G., Thøgersen, I.B., Valnickova, Z., Pizzo, S. V, and Hefta, S.A. (1993). Presence of the protein-glycosaminoglycan-protein covalent cross-link in the inter-alpha-inhibitor-related proteinase inhibitor heavy chain 2/bikunin. J. Biol. Chem. 268, 8711-8716. Enghild, J.J., Thøgersen, I.B., Cheng, F., Fransson, L.Å., Roepstorff, P., and Rahbek-Nielsen, H. (1999). Organization of the inter- $\alpha$-inhibitor heavy chains on the chondroitin sulfate originating from Ser10 of bikunin: Posttranslational modification of I $\alpha$ I-derived bikunin. Biochemistry 38, 11804-11813.

Evans, P.R. (2011). An introduction to data reduction: space-group determination, scaling and intensity statistics. Acta Crystallogr. D. Biol. Crystallogr. 67, 282-292.

Evans, P. (2006). Scaling and assessment of data quality. Acta Crystallogr. Sect. D Biol. Crystallogr. 62, $72-$ 82.

Evans, P.R., and Murshudov, G.N. (2013). How good are my data and what is the resolution? Acta Crystallogr. Sect. D Biol. Crystallogr. 69, 1204-1214.

Forneris, F., Ricklin, D., Wu, J., Tzekou, A., Wallace, R.S., Lambris, J.D., and Gros, P. (2010). Structures of $\mathrm{C} 3 \mathrm{~b}$ in complex with factors $\mathrm{B}$ and $\mathrm{D}$ give insight into complement convertase formation. Science 330, $1816-1820$.

Franke, D., and Svergun, D.I. (2009). DAMMIF, a program for rapidab-initioshape determination in smallangle scattering. J. Appl. Crystallogr. 42, 342-346.

Fu, S., Tong, X., Cai, C., Zhao, Y., Wu, Y., Li, Y., Xu, J., Zhang, X.C., Xu, L., Chen, W., et al. (2010). The structure of tumor endothelial marker 8 (TEM8) extracellular domain and implications for its receptor function for recognizing anthrax toxin. PLoS One 5, e1 1203.

Fülöp, C., Szántó, S., Mukhopadhyay, D., Bárdos, T., Kamath, R. V, Rugg, M.S., Day, A.J., Salustri, A., Hascall, V.C., Glant, T.T., et al. (2003). Impaired cumulus mucification and female sterility in tumor necrosis factor-induced protein-6 deficient mice. Development 130, 2253-2261.

Garantziotis, S., Hollingsworth, J.W., Ghanayem, R.B., Timberlake, S., Zhuo, L., Kimata, K., and Schwartz, D.A. (2007). Inter-alpha-trypsin inhibitor attenuates complement activation and complement-induced lung injury. J. Immunol. 179, 4187-4192.

Houtman, J.C.D., Brown, P.H., Bowden, B., Yamaguchi, H., Appella, E., Samelson, L.E., and Schuck, P. (2007). Studying multisite binary and ternary protein interactions by global analysis of isothermal titration calorimetry data in SEDPHAT: application to adaptor protein complexes in cell signaling. Protein Sci. 16, $30-42$.

Inforzato, A., Rivieccio, V., Morreale, A.P., Bastone, A., Salustri, A., Scarchilli, L., Verdoliva, A., Vincenti, S., Gallo, G., Chiapparino, C., et al. (2008). Structural characterization of PTX3 disulfide bond network and its multimeric status in cumulus matrix organization. J. Biol. Chem. 283, 10147-10161. 
evolution of immunity. Nature 437, 505-511.

Jürgens, M.C., Vörös, J., Rautureau, G.J.P., Shepherd, D.A., Pye, V.E., Muldoon, J., Johnson, C.M., Ashcroft, A.E., Freund, S.M. V, and Ferguson, N. (2013). The hepatitis B virus preS1 domain hijacks host trafficking proteins by motif mimicry. Nat. Chem. Biol. 9, 540-547.

Kaczmarczyk, A., Thuveson, M., and Fries, E. (2002). Intracellular coupling of the heavy chain of pre-alphainhibitor to chondroitin sulfate. J. Biol. Chem. 277, 13578-13582.

Kelley, L.A., Mezulis, S., Yates, C.M., Wass, M.N., and Sternberg, M.J.E. (2015). The Phyre2 web portal for protein modeling, prediction and analysis. Nat. Protoc. 10, 845-858.

Konarev, P. V., Volkov, V. V., Sokolova, A. V., Koch, M.H.J., and Svergun, D.I. (2003). PRIMUS: a Windows PC-based system for small-angle scattering data analysis. J. Appl. Crystallogr. 36, 1277-1282.

Lacy, D.B., Wigelsworth, D.J., Scobie, H.M., Young, J.A.T., and Collier, R.J. (2004). Crystal structure of the von Willebrand factor A domain of human capillary morphogenesis protein 2: an anthrax toxin receptor. Proc. Natl. Acad. Sci. U. S. A. 101, 6367-6372.

Leaver-Fay, A., Tyka, M., Lewis, S.M., Lange, O.F., Thompson, J., Jacak, R., Kaufman, K., Renfrew, P.D., Smith, C.A., Sheffler, W., et al. (2011). ROSETTA3: an object-oriented software suite for the simulation and design of macromolecules. Methods Enzymol. 487, 545-574.

Liu, S., Zhang, Y., Hoover, B., and Leppla, S. (2012). The receptors that mediate the direct lethality of anthrax toxin. Toxins (Basel). 5, 1-8.

Luo, B.-H., Carman, C. V., and Springer, T.A. (2007). Structural basis of integrin regulation and signaling. Annu. Rev. Immunol. 25, 619-647.

Ly, M., Leach, F.E., Laremore, T.N., Toida, T., Amster, I.J., and Linhardt, R.J. (2011). The proteoglycan bikunin has a defined sequence. Nat. Chem. Biol. 7, 827-833.

Martin, J., Midgley, A., Meran, S., Woods, E., Bowen, T., Phillips, A.O., and Steadman, R. (2016). Tumor necrosis factor-stimulated gene 6 (TSG-6)-mediated interactions with the inter- $\alpha$-inhibitor heavy chain 5 facilitate tumor growth factor $\beta 1$ (TGF $\beta 1$ )-dependent fibroblast to myofibroblast differentiation. J. Biol. Chem. 291, 13789-13801.

Morelle, W., Capon, C., Balduyck, M., Sautiere, P., Kouach, M., Michalski, C., Fournet, B, and Mizon, J. (1994). Chondroitin sulphate covalently cross-links the three polypeptide chains of inter-alpha-trypsin inhibitor. Eur. J. Biochem. 221, 881-888.

Mukhopadhyay, D., Hascall, V.C., Day, A.J., Salustri, A., and Fülöp, C. (2001). Two distinct populations of tumor necrosis factor-stimulated gene-6 protein in the extracellular matrix of expanded mouse cumulus celloocyte complexes. Arch. Biochem. Biophys. 394, 173-181. Nagyova, E. (2015). Organization of the expanded cumulus-extracellular matrix in preovulatory follicles: a role for inter-alpha-trypsin inhibitor. Endocr. Regul. 49, 37-45. function of tumor necrosis factor-alpha-stimulated gene 6 blocks cumulus cell-oocyte complex expansion. Endocrinology 144, 4376-4384.

Ogawa, Y., He, H., Mukai, S., Imada, T., Nakamura, S., Su, C.-W., Mahabole, M., Tseng, S.C.G., and 
Tsubota, K. (2017). Heavy chain-hyaluronan/pentraxin 3 from amniotic membrane suppresses inflammation and scarring in murine lacrimal gland and conjunctiva of chronic graft-versus-host disease. Sci. Rep. 7, 42195 .

Okroj, M., Holmquist, E., Sjölander, J., Corrales, L., Saxne, T., Wisniewski, H.-G., and Blom, A.M. (2012). Heavy chains of inter alpha inhibitor ( $\mathrm{I} \alpha \mathrm{I}$ ) inhibit the human complement system at early stages of the cascade. J. Biol. Chem. 287, 20100-20110.

Olsen, E.H.N., Rahbek-Nielsen, H., Thøgersen, I.B., Roepstorff, P., and Enghild, J.J. (1998). Posttranslational modifications of human inter- $\alpha$-inhibitor: Identification of glycans and disulfide bridges in heavy chains 1 and 2. Biochemistry 37, 408-416.

Opal, S.M., Artenstein, A.W., Cristofaro, P.A., Jhung, J.W., Palardy, J.E., Parejo, N.A., and Lim, Y.-P. (2005). Inter-alpha-inhibitor proteins are endogenous furin inhibitors and provide protection against experimental anthrax intoxication. Infect. Immun. 73, 5101-5105.

Opal, S.M., Lim, Y.-P., Cristofaro, P., Artenstein, A.W., Kessimian, N., Delsesto, D., Parejo, N., Palardy, J.E., and Siryaporn, E. (2011). Inter- $\alpha$ inhibitor proteins: a novel therapeutic strategy for experimental anthrax infection. Shock 35, 42-44.

16 Parente, R., Clark, S.J., Inforzato, A., and Day, A.J. (2017). Complement factor H in host defense and immune evasion. Cell. Mol. Life Sci. 74, 1605-1624.

Petoukhov, M. V., Konarev, P. V., Kikhney, A.G., and Svergun, D.I. (2007). ATSAS 2.1 - towards automated and web-supported small-angle scattering data analysis. J. Appl. Crystallogr. 40, s223-s228.

Preissner, K., and Reuning, U. (2011). Vitronectin in Vascular Context: Facets of a Multitalented Matricellular Protein. Semin. Thromb. Hemost. 37, 408-424.

Ricklin, D., Reis, E.S., and Lambris, J.D. (2016). Complement in disease: a defence system turning offensive. Nat. Rev. Nephrol. 12, 383-401.

Robertson, I.B., Horiguchi, M., Zilberberg, L., Dabovic, B., Hadjiolova, K., and Rifkin, D.B. (2015). Latent TGF- $\beta$-binding proteins. Matrix Biol. 47, 44-53.

Rugg, M.S., Willis, A.C., Mukhopadhyay, D., Hascall, V.C., Fries, E., Fülöp, C., Milner, C.M., and Day, A.J. (2005). Characterization of complexes formed between TSG-6 and inter-alpha-inhibitor that act as intermediates in the covalent transfer of heavy chains onto hyaluronan. J. Biol. Chem. 280, 25674-25686.

Russell, D., and Salustri, A. (2006). Extracellular Matrix of the Cumulus-Oocyte Complex. Semin. Reprod. Med. 24, 217-227.

Salustri, A., Garlanda, C., Hirsch, E., De Acetis, M., Maccagno, A., Bottazzi, B., Doni, A., Bastone, A., Mantovani, G., Beck Peccoz, P., et al. (2004). PTX3 plays a key role in the organization of the cumulus oophorus extracellular matrix and in in vivo fertilization. Development 131, 1577-1586. Morishita, H., Niwa, H., et al. (2001). Impaired fertility in female mice lacking urinary trypsin inhibitor. Biochem. Biophys. Res. Commun. 281, 1154-1160. 
inhibitor is maintained by the chondroitin sulfate chain and divalent cations. J. Biol. Chem. 291, 4658-4670.

Schuck, P. (2000). Size-distribution analysis of macromolecules by sedimentation velocity ultracentrifugation and lamm equation modeling. Biophys. J. 78, 1606-1619.

Shi, M., Zhu, J., Wang, R., Chen, X., Mi, L., Walz, T., and Springer, T.A. (2011). Latent TGF- $\beta$ structure and activation. Nature 474, 343-351.

Singh, K., Zhang, L.X., Bendelja, K., Heath, R., Murphy, S., Sharma, S., Padbury, J.F., and Lim, Y.-P. (2010). Inter-alpha inhibitor protein administration improves survival from neonatal sepsis in mice. Pediatr. Res. 68, 242-247.

Svergun, D.I. (1999). Restoring low resolution structure of biological macromolecules from solution scattering using simulated annealing. Biophys. J. 76, 2879-2886.

11 Svergun, D.I. (1992). Determination of the regularization parameter in indirect-transform methods using perceptual criteria. J. Appl. Crystallogr. 25, 495-503.

Terwilliger, T.C., Adams, P.D., Read, R.J., McCoy, A.J., Moriarty, N.W., Grosse-Kunstleve, R.W., Afonine, P. V., Zwart, P.H., and Hung, L.-W. (2009). Decision-making in structure solution using Bayesian estimates of map quality: the PHENIX AutoSol wizard. Acta Crystallogr. Sect. D Biol. Crystallogr. 65, 582-601.

16 Troilo, H., Steer, R., Collins, R.F., Kielty, C.M., and Baldock, C. (2016). Independent multimerization of 17 Latent TGF $\beta$ Binding Protein-1 stabilized by cross-linking and enhanced by heparan sulfate. Sci. Rep. 6, 34347.

19 Tuukkanen, A.T., Kleywegt, G.J., and Svergun, D.I. (2016). Resolution of ab initio shapes determined from small-angle scattering. IUCrJ 3, 440-447.

Wahle, M., and Wriggers, W. (2015). Multi-scale visualization of molecular architecture using real-time ambient occlusion in sculptor. PLoS Comput. Biol. 11, e1004516.

Wang, Z., Thinn, A.M.M., and Zhu, J. (2017). A pivotal role for a conserved bulky residue at the $\alpha 1$-helix of the $\alpha \mathrm{I}$ integrin domain in ligand binding. J. Biol. Chem. 292, 20756-20768.

Waterman, D.G., Winter, G., Gildea, R.J., Parkhurst, J.M., Brewster, A.S., Sauter, N.K., and Evans, G. (2016). Diffraction-geometry refinement in the DIALS framework. Acta Crystallogr. Sect. D Struct. Biol. 72, $558-575$.

Weinkam, P., Pons, J., and Sali, A. (2012). Structure-based model of allostery predicts coupling between distant sites. Proc. Natl. Acad. Sci. U. S. A. 109, 4875-4880.

Winter, G., Lobley, C.M.C., and Prince, S.M. (2013). Decision making in xia2. Acta Crystallogr. D. Biol. Crystallogr. 69, 1260-1273.

Worthington, J.J., Kelly, A., Smedley, C., Bauché, D., Campbell, S., Marie, J.C., and Travis, M.A. (2015). Integrin $\alpha v \beta 8$-mediated TGF- $\beta$ activation by effector regulatory $\mathrm{T}$ cells is essential for suppression of T-cellmediated inflammation. Immunity 42, 903-915. inhibitor complex: A serine protease inhibitor with two kunitz domains. J. Mol. Biol. 276, 955-966. 
1 characterization of the complex in synovial fluid from patients with rheumatoid arthritis. J. Biol. Chem. 278,

$2 \quad 32710-32718$.

3 Zhang, S., He, H., Day, A.J., and Tseng, S.C.G. (2012). Constitutive expression of inter- $\alpha$-inhibitor (I $\alpha \mathrm{I})$

4 family proteins and tumor necrosis factor-stimulated gene-6 (TSG-6) by human amniotic membrane

5 epithelial and stromal cells supporting formation of the heavy chain-hyaluronan (HC-HA) complex. J. Biol.

6 Chem. 287, 12433-12444.

7 Zhao, M., Yoneda, M., Ohashi, Y., Kurono, S., Iwata, H., Ohnuki, Y., and Kimata, K. (1995). Evidence for

8 the covalent binding of SHAP, heavy chains of inter-alpha-trypsin inhibitor, to hyaluronan. J. Biol. Chem.

$9270,26657-26663$.

10 Zhuo, L., Yoneda, M., Zhao, M., Yingsung, W., Yoshida, N., Kitagawa, Y., Kawamura, K., Suzuki, T., and

11 Kimata, K. (2001). Defect in SHAP-hyaluronan complex causes severe female infertility. A study by

12 inactivation of the bikunin gene in mice. J. Biol. Chem. 276, 7693-7696.

13 Zhuo, L., Hascall, V.C., and Kimata, K. (2004). Inter-alpha-trypsin inhibitor, a covalent protein14 glycosaminoglycan-protein complex. J. Biol. Chem. 279, 38079-38082.

15 Zhuo, L., Kanamori, A., Kannagi, R., Itano, N., Wu, J., Hamaguchi, M., Ishiguro, N., and Kimata, K. (2006).

16 SHAP potentiates the CD44-mediated leukocyte adhesion to the hyaluronan substratum. J. Biol. Chem. 281, $17 \quad 20303-20314$. 


\section{Figure Legends}

Figure 1: The crystal structure of HC1. A) Orthogonal views of the structure of $\mathrm{rHC1}$, coloured from N(blue) to $\mathrm{C}$ - (red) terminus, where domains and the bound $\mathrm{Mg}^{2+}$ ion are labelled; the dotted red line denotes resides 631-636, which are not visible in the crystal structure. B) Close up of the MIDAS site, showing metal co-ordination (black) and an important hydrogen bond (grey). The WT structure is shown in green and D298A structure (which lacks a $\mathrm{Mg}^{2+}$ ion) in pink. C) Raw SAXS data (orange with black error bars) of a rHC1 monomer (D298A), and back-calculated scattering curves based on the crystal structure of rHC1 alone or the crystal structure with the unstructured/flexible regions modelled in using Allosmod. D) Allosmod model of rHC1 with the N-terminal histidine tag (blue) and residues 35-44, 631-636 and 653-672 (pink) modelled based on SAXS restraints.

Figure 2: Integrin-like arrangement of vWFa and Hydrid1 domains in HC1 structure. A) Topologies of the HC-Hybrid1 domain from HC1 (left) and the hybrid domain from human integrin $\beta 3$ chain (ITGB3) (right); the arrangements of $\beta$-strands in the sequences following the vWFa domains are essentially identical (dashed red box). B) Side-by-side views of the 'hybrid' and vWFa domain pairs of HC1 (left) and ITGB3 (right). C) The 'hybrid' domains are displaced by $\sim 40^{\circ}$ when the vWFa domains of HC1 and ITGB3 are superimposed.

Figure 3: HC1 forms metal ion-dependent dimers. A) A plot of sedimentation coefficient distributions (c(s)) vs s(apparent)) for WT rHC1 derived from velocity AUC analysis. In the presence of 2.5mM EDTA (orange), $93 \%$ of the $\mathrm{rHC} 1$ protein is in a monomeric state $\left(\mathrm{s}_{(20, \mathrm{w})}=4.39 \mathrm{~S}\right)$ and there is no detectable dimer present; in $5 \mathrm{mM} \mathrm{MgCl}_{2}$ (blue) $64 \%$ of the protein is monomeric $\left(\mathrm{s}_{(20, \mathrm{w})}=4.59 \mathrm{~S}\right)$ and $21 \%$ of material is dimeric $\left(\mathrm{s}_{(20, w)}=6.11 \mathrm{~S}\right)$. B) Plot of $\log _{10} K_{\mathrm{D}}$ vs $\mathrm{MgCl}_{2}$ concentration, derived from equilibrium AUC measurements. At $0 \mathrm{mM} \mathrm{MgCl}_{2}$ (achieved by conducting the experiment in $2.5 \mathrm{mM}$ EDTA) no dimerisation was detected. Maximal binding affinity (for self-association of the $\mathrm{rHC} 1$ dimer) was reached at $\sim 1 \mathrm{mM}$ $\mathrm{MgCl}_{2}$, i.e. close to the concentration of free $\mathrm{Mg}^{2+}$ ions in plasma. C) Ab initio SAXS models for the $\mathrm{HC} 1$ monomer (left) and dimer (right) where the $\mathrm{HC} 1$ structure has been modelled into the SAXS envelopes. D) Buffer-subtracted SAXS scattering curves for HC1 D298 monomer (orange) and WT dimer (blue) and E) their derived P(r) vs Distance plots, consistent with WT HC1 forming an elongated $\mathrm{Mg}^{2+}$-dependent dimer and the MIDAS site mutant (D298A) being monomeric.

Figure 4: The quaternary structure of inter- $\alpha$-inhibitor. A) Raw SAXS data for I $\alpha$ (obs) in the presence of $2 \mathrm{mM} \mathrm{MgCl} 2$ fitted to scattering data (pink with black error bars) derived from the pseudo atomic model (model) in (C) calculated using Allosmod-FoXs. B) P(r) vs Distance plot showing that $\mathrm{I} \alpha \mathrm{I}$ has an elongated and asymmetric shape. C) Orthogonal views of the SAXS envelope of I $\alpha$ I (transparent grey surface) determined ab initio from the SAXS scattering curve, with structures of bikunin (PDB 1BIK; pink) and rHC1 (determined here; brown) and a threading model of $\mathrm{HC} 2$ (based upon the structure of $\mathrm{HC} 1$; blue), modelled 
1 in. The CS chain is shown schematically to indicate its expected position relative to the three protein chains.

2 Figure 5: $\mathrm{HC1}$ inhibits the alternative pathway $\mathrm{C3}$ convertase activity through interaction with $\mathrm{C3}$. A)

3 SPR analysis for the interaction of $\mathrm{rHC} 1$ (WT and D298A) with $\mathrm{C} 3$ (in $2 \mathrm{mM} \mathrm{MnCl}_{2}$ ), where the lack of

4 binding of the D298A mutant indicates an essential role for the MIDAS site. B) rHC1 proteins (WT and

5 D298A) were compared with factor $\mathrm{H}(\mathrm{FH})$ in an alternative pathway $\mathrm{C} 3$ convertase assay (containing $\mathrm{Mg}^{2+}$

6 and $\mathrm{Mn}^{2+}$ ions), where the proteolytic release of C3a was quantified (by SDS-PAGE) as a surrogate for the

7 conversion of $\mathrm{C} 3$ into C3b. Only WT rHC1 had inhibitory activity; data for D298A, not shown. Mean values

$8 \quad( \pm \mathrm{SD})$ were derived from independent experiments performed in triplicate. Data were fitted using Graphpad

9 Prism to derive $\mathrm{IC}_{50}$ values for $\mathrm{rHC} 1$ and $\mathrm{FH}$ control. C) An in silico model of the $\mathrm{C} 3 \mathrm{C}$-terminal $\mathrm{C} 345 \mathrm{C}$

10 domain (pink) bound to the vWFa domain of $\mathrm{HC} 1$ (blue). Here a $\mathrm{Mn}^{2+}$ ion (green) occupies the MIDAS of

$11 \mathrm{HC1}$ (with co-ordinating residues shown in stick representation) and co-chelates the carboxy-terminal amino

12 acid (Asn) of C3b. D) An ab initio SAXS structure was determined for the rHC1-C3 complex (red mesh),

13 where $\mathrm{C} 3$ and $\mathrm{HC} 1$ molecules, interacting as in $(\mathbf{C})$, could be accommodated. 
bioRxiv preprint doi: https://doi.org/10.1101/695700; this version posted July 8, 2019. The copyright holder for this preprint (which was not certified by peer review) is the author/funder, who has granted bioRxiv a license to display the preprint in perpetuity. It is made available under aCC-BY-NC-ND 4.0 International license.

1 Table 1. Data collection and refinement statistics for $\mathbf{r H C 1}$.

\begin{tabular}{|c|c|c|}
\hline & WT - 6FPY & D298A - 6FPZ \\
\hline Wavelength & $0.92 \AA$ & $0.92 \AA$ \\
\hline Resolution range & $71-2.3(2.4-2.3)^{\mathrm{a}}$ & $56.8-2.2(2.3-2.2)$ \\
\hline Space group & $\mathrm{P} 42$ & P 42 \\
\hline Unit cell & 158.8158 .865 .4909090 & 159.7159 .765 .79909090 \\
\hline Total reflections & 455794 (45882) & 312045 (26776) \\
\hline Unique reflections & $69109(6862)$ & $83837(8233)$ \\
\hline Multiplicity & $6.6(6.7)$ & $3.7(3.3)$ \\
\hline Completeness (\%) & $91.94(87.58)$ & $94.27(88.13)$ \\
\hline Mean I/sigma(I) & $8.02(1.88)$ & $10.93(2.05)$ \\
\hline Wilson B-factor & 37.46 & 34.70 \\
\hline R-merge & $0.1432(0.8002)$ & $0.06619(0.4731)$ \\
\hline R-meas & $0.1554(0.8681)$ & $0.07734(0.5596)$ \\
\hline R-pim & $0.05991(0.3337)$ & $0.03928(0.2917)$ \\
\hline $\mathrm{CC} 1 / 2$ & $0.994(0.523)$ & $0.995(0.478)$ \\
\hline $\mathrm{CC}^{*}$ & $0.998(0.829)$ & $0.999(0.804)$ \\
\hline $\begin{array}{l}\text { Reflections used in } \\
\text { refinement }\end{array}$ & $63610(6027)$ & 79667 (7405) \\
\hline Reflections used for R-free & $3194(306)$ & $3983(347)$ \\
\hline R-work & $0.2317(0.3810)$ & $0.2174(0.3701)$ \\
\hline R-free & $0.2605(0.4195)$ & $0.2475(0.3641)$ \\
\hline CC(work) & $0.953(0.726)$ & $0.954(0.730)$ \\
\hline $\mathrm{CC}($ free $)$ & $0.946(0.696)$ & $0.948(0.768)$ \\
\hline $\begin{array}{l}\text { Number of non-hydrogen } \\
\text { atoms }\end{array}$ & 9702 & 10106 \\
\hline
\end{tabular}


bioRxiv preprint doi: https://doi.org/10.1101/695700; this version posted July 8, 2019. The copyright holder for this preprint (which was not certified by peer review) is the author/funder, who has granted bioRxiv a license to display the preprint in perpetuity. It is made available under aCC-BY-NC-ND 4.0 International license.

\begin{tabular}{|c|c|c|}
\hline macromolecules & 9319 & 9335 \\
\hline ligands & 38 & 58 \\
\hline solvent & 345 & 713 \\
\hline Protein residues & 1201 & 1196 \\
\hline RMS(bonds) & 0.004 & 0.003 \\
\hline RMS(angles) & 1.03 & 0.92 \\
\hline $\begin{array}{l}\text { Ramachandran favoured } \\
(\%)\end{array}$ & 97.65 & 98.15 \\
\hline Ramachandran allowed (\%) & 2.27 & 1.85 \\
\hline Ramachandran outliers (\%) & 0.08 & 0.00 \\
\hline Rotamer outliers (\%) & 1.20 & 1.00 \\
\hline Clashscore & 1.78 & 1.71 \\
\hline Average B-factor & 49.67 & 45.75 \\
\hline macromolecules & 49.92 & 45.76 \\
\hline ligands & 62.82 & 71.64 \\
\hline solvent & 41.55 & 43.54 \\
\hline Number of TLS groups & 8 & 6 \\
\hline
\end{tabular}

$1 \quad$ a Statistics for the highest-resolution shell are shown in parentheses. 
bioRxiv preprint doi: https://doi.org/10.1101/695700; this version posted July 8, 2019. The copyright holder for this preprint (which was not certified by peer review) is the author/funder, who has granted bioRxiv a license to display the preprint in perpetuity. It is made available under aCC-BY-NC-ND 4.0 International license.

1 Table 2. Biophysical analysis of rHC1 dimerisation. Radius of gyration $\left(\mathrm{R}_{\mathrm{g}}\right)$, maximum dimension $\left(\mathrm{D}_{\mathrm{max}}\right)$,

2 approximate molecular weight $(\mathrm{Mwt})$ and sedimentation coefficient $\left(\mathrm{s}_{\mathrm{w}(20, \mathrm{w})}\right)$ values were derived from

3 SAXS and AUC data for WT and D298A rHC1. All D298A data, and WT data collected in the presence of $42.5 \mathrm{mM}$ EDTA, are consistent with a monomeric state. WT $\mathrm{rHCl}$ with $5 \mathrm{mM} \mathrm{MgCl}_{2}$ or $5 \mathrm{mM} \mathrm{MnCl}_{2}$ is 5 dimeric. Data from "As purified" WT $\mathrm{rHC} 1$ and in $5 \mathrm{mM} \mathrm{CaCl} 2$ are consistent with a mixture of monomer 6 and dimer; this is presumably due to trace amounts of $\mathrm{Mg}^{2+}$ ions present in various buffer components. AUC 7 data are derived from equilibrium experiments performed in triplicate at 3 different speeds; SAXS data are 8 from data processed by AUTORG and with DATGNOM (i.e. with no imposed constraints). The molecular 9 weight of an rHC1 monomer from intact mass spectrometry is 73,802 Da.

10

\begin{tabular}{|c|c|c|c|c|c|c|}
\hline Protein & Metal ion & 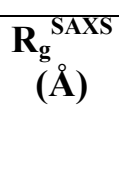 & $\begin{array}{c}\mathbf{D}_{\max } \text { SAXS } \\
(\AA)\end{array}$ & $\begin{array}{c}\text { Mwt }^{\text {SAXS }} \\
(\mathbf{k D a})^{\mathbf{b}} \\
\text { (Ratio SAXS }_{\text {mass/Intact mass) }}\end{array}$ & $\begin{array}{l}\mathbf{S}_{(20, w)}^{\text {AUC }} \\
\text { (S) }\end{array}$ & $\begin{array}{l}\mathbf{S}_{(20, w)} \text { SAXS } \\
\text { (S) }\end{array}$ \\
\hline \multirow[t]{4}{*}{ rHC1 WT } & None $^{a}$ & 35.2 & 123 & & & \\
\hline & $\begin{array}{c}\text { EDTA } \\
(2.5 \mathrm{mM})\end{array}$ & 31.8 & 112 & $\begin{array}{c}78 \\
(1.06) \\
\end{array}$ & 4.39 & 4.50 \\
\hline & $\mathrm{Mg}^{2+}(5 \mathrm{mM})$ & 49.5 & 170 & $\begin{array}{c}140 \\
(1.89)\end{array}$ & $\begin{array}{c}4.59 \text { (monomer) } \\
6.11 \text { (dimer) }\end{array}$ & 6.24 \\
\hline & $\mathrm{Mn}^{2+}(5 \mathrm{mM})$ & 51.2 & 172 & & & \\
\hline & $\mathrm{Ca}^{2+}(5 \mathrm{mM})$ & 38.5 & 135 & & & \\
\hline \multirow[t]{4}{*}{$\mathrm{rHC1} \mathrm{D} 298 \mathrm{~A}$} & None $^{\mathrm{a}}$ & 33.3 & 114 & & & \\
\hline & $\mathrm{Mg}^{2+}(5 \mathrm{mM})$ & 33.3 & 114 & & & \\
\hline & $\mathrm{Mn}^{2+}(5 \mathrm{mM})$ & 32.8 & 105 & & & \\
\hline & $\mathrm{Ca}^{2+}(5 \mathrm{mM})$ & 32.8 & 115 & & & \\
\hline $\mathrm{I} \alpha \mathrm{I}$ & $\mathrm{Mg}^{2+}(5 \mathrm{mM})$ & 49.2 & 170 & & & \\
\hline
\end{tabular}

$11{ }^{\mathrm{a}}$ As purified

12 b Calculated using the method of Rambo \& Tainer (2013) Nature 496, 477-481 
bioRxiv preprint doi: https://doi.org/10.1101/695700; this version posted July 8,2019 . The copyright holder for this preprint (which was not certified by peer review) is the author/funder, who has granted bioRxiv a license to display the preprint in perpetuity. It is made available under aCC-BY-NC-ND 4.0 International license.

Table 3. Analysis of rHC1-ligand interactions by SPR.

Immobilised ligand Analyte Buffer conditions

C3

$\mathrm{C} 3$

$\mathrm{C} 3$

$\mathrm{C} 3$

rHC1 (WT)

rHC1 (WT)

rHC1 (D298A)

rHC1 (D298A)

$\mathrm{rHC} 1(\Delta \mathrm{vWFa})$

rHC1 (WT)

rHC1 (D298A)

rHC1 (WT)

rHC1 (D298A)

rHC1 (WT)

rHC1 (D298A)

rHC1 (WT)

rHC1 (WT)

rHC1 (WT)

rHC1 (WT)

rHC1 (WT)

rHC1 (WT)

rHC1 (WT)

${ }^{\mathrm{a}} \mathrm{NB}=$ no binding
$\mathrm{rHCl}(\mathrm{WT}) \quad 2 \mathrm{mM} \mathrm{Mg}^{2+} / 2 \mathrm{mM} \mathrm{Mn}^{2+}$

$\mathrm{rHCl}$ (WT) $2 \mathrm{mM} \mathrm{Mn}^{2+}$

rHC1 (D298A) $2 \mathrm{mM} \mathrm{Mg}^{2+} / 2 \mathrm{mM} \mathrm{Mn}^{2+}$

$\mathrm{I} \alpha \mathrm{I}$

$2 \mathrm{mM} \mathrm{Mg}^{2+} / 2 \mathrm{mM} \mathrm{Mn}^{2+}$

Vitronectin

Vitronectin

Vitronectin

Vitronectin

$2 \mathrm{mM} \mathrm{Mg}^{2+} / 2 \mathrm{mM} \mathrm{Mn}^{2+}$ $10 \mathrm{mM}$ EDTA

$2 \mathrm{mM} \mathrm{Mg}^{2+} / 2 \mathrm{mM} \mathrm{Mn}^{2+}$

Vitronectin

$10 \mathrm{mM}$ EDTA

TGF 31 -LAP $2 \mathrm{mM} \mathrm{Mg}^{2+} / 2 \mathrm{mM} \mathrm{Mn}^{2+}$

TGF $\beta 1$-LAP $2 \mathrm{mM} \mathrm{Mg}^{2+} / 2 \mathrm{mM} \mathrm{Mn}^{2+}$

TGF 32 -LAP $2 \mathrm{mM} \mathrm{Mg}^{2+} / 2 \mathrm{mM} \mathrm{Mn}^{2+}$

TGF 32 -LAP $\quad 2 \mathrm{mM} \mathrm{Mg}^{2+} / 2 \mathrm{mM} \mathrm{Mn}^{2+}$

TGF 33 -LAP $\quad 2 \mathrm{mM} \mathrm{Mg}^{2+} / 2 \mathrm{mM} \mathrm{Mn}^{2+}$

TGF 33 -LAP $2 \mathrm{mM} \mathrm{Mg}^{2+} / 2 \mathrm{mM} \mathrm{Mn}^{2+}$

LAP (TGF $\beta 1) \quad 10 \mathrm{mM}$ EDTA

TGF $\beta 1$

$10 \mathrm{mM}$ EDTA

TGF $\beta 3$

$10 \mathrm{mM}$ EDTA

LTBP1 NT1

LTBP1 NT1

$10 \mathrm{mM}$ EDTA

LTBP1 EGF

$2 \mathrm{mM} \mathrm{Mg}^{2+} / 2 \mathrm{mM} \mathrm{Mn}^{2+}$

LTBP1 CT
10mM EDTA

\section{Replicates}

$K_{\mathrm{D}}(\mathrm{nM}) \pm \mathrm{SD}$

$364 \pm 78$

$473 \pm 329$

$\mathrm{NB}^{\mathrm{a}}$

$659 \pm 205$

$0.192 \pm 0.014$

$0.118 \pm 0.011$

$0.138 \pm 0.040$

$0.096 \pm 0.044$

$0.097 \pm 0.049$

$16.1 \pm 5.5$

$14.9 \pm 2.7$

$8.8 \pm 0.6$

$12.9 \pm 1.7$

$9.9 \pm 1.4$

$3.1 \pm 0.8$

$2.0 \pm 0.3$

NB

NB

$5.1 \pm 0.5$

$4.6 \pm 0.2$

NB

NB 
Supplementary Figure Legends

Supplementary Figure S1: Schematics of $I \alpha I$ and P $\alpha$ I, TSG-6-mediated HC transfer, and domain organisations for HCs 1-3. A) A schematic illustrating the organisation of $I \alpha I$ and $P \alpha I$ showing that these proteoglycan both contain the bikunin core protein to which a chondroitin sulphate (CS) chain is attached via a typical tetrasaccharide linkage; heavy chains $(\mathrm{HC} 1$ and $\mathrm{HC} 2$ in $\mathrm{I} \alpha \mathrm{I}$ and $\mathrm{HC} 3$ in $\mathrm{P} \alpha \mathrm{I})$ are linked to $\mathrm{CS}$ via ester bonds (red circles) formed between their C-terminal aspartic acid residues and a C6 hydroxyl within a $\mathrm{N}$-acetyl galactosamine sugar in CS. In the presence of hyaluronan (HA), which is composed of a variable number (n) of repeating disaccharides of glucuronic acid (diamonds) and $\mathrm{N}$-acetyl glucosamine (squares), and the trans-esterase TSG-6, HCs are covalently transferred from $\mathrm{I} \alpha \mathrm{I} / \mathrm{P} \alpha \mathrm{I}$ onto $\mathrm{HA}$ to form $\mathrm{HC} \cdot \mathrm{HA}$ complexes; ester bonds link the C-terminal aspartic acids of the HCs to $\mathrm{N}$-acetyl glucosamine residues of HA. B) A schematic of the domain organisation of the mature $\mathrm{HC} 1$ protein (residues 35-672 in Uniprot P19827), as determined from the crystal structure described here, along with their corresponding structural elements. The $\mathrm{N}$ - and C-terminal regions associate to form the Hybrid2 domain and the vWFA domain is flanked by H-sequences that constitute the Hybrid1 domain; the position of the D298A mutant is indicated along with the region that is deleted in the $\triangle$ vWFA construct. The domain organisations of the mature HC2 and $\mathrm{HC} 3$ proteins can be inferred from their homology with $\mathrm{HC} 1$ (39\% and 54\% identity, respectively).

Supplementary Figure 2: Equilibrium AUC on $\mathbf{r H C 1}$ in absence and presence of $\mathbf{M g C l}_{2}$ ions. Three concentrations of $\mathrm{rHC} 1(4,11$ and $22 \mu \mathrm{M})$ were analysed by equilibrium $\mathrm{AUC}$ at rotor speeds of 10,000 (pink), 15,000 (blue) and 20,000 (cyan) rpm in the absence (2.5 mM EDTA) or presence of $0.1,0.5,1$ or $5 \mathrm{mM} \mathrm{MgCl}_{2}$. High speed data for $11 \mu \mathrm{M} \mathrm{HC} 1$ in $1 \mathrm{mM} \mathrm{MgCl}_{2}$ were omitted.

Supplementary Figure S3: SAXS data analysis for HC1 monomer (blue) and dimer (orange). A) Analysis of the Guinier region and residuals. B) Dimensionless Kratky plots show that HC1 monomer and dimer molecules are folded and globular; the cross-hairs denote the globularity point, and the shift of the maxima for the $\mathrm{HC} 1$ dimer to the right indicate that it is more extended and asymmetric than the monomer. SIBYLS (C) and Porod-Debye (D) plots indicate that the HC1 monomer and dimer are rigid.

Supplementary Figure S4: SAXS data analysis for I $\alpha \mathbf{I}$. A) Analysis of the Guinier region and residuals.

B) Dimensionless Kratky plots show that all of I $\alpha \mathrm{I}$ is folded, globular, but asymmetric as revealed by the maxima being to the right of the globularity point (cross-hairs). SIBYLS (C) and Porod-Debye (D) plots demonstrate that $I \alpha I$ is rigid. region and residuals. B) A Dimensionless Kratky plot reveals that the rHC1-C3 complex is folded, globular, (C) and Porod-Debye (D) plots indicate that the rHC1-C3 complex has some flexibility. 
bioRxiv preprint doi: https://doi.org/10.1101/695700; this version posted July 8, 2019. The copyright holder for this preprint (which was not certified by peer review) is the author/funder, who has granted bioRxiv a license to display the preprint in perpetuity. It is made available under aCC-BY-NC-ND 4.0 International license.

1 Supplementary Figure S6: MIDAS-independent binding of HC1 to vitronectin and TGF $\beta$-LAP

2 proteins. SPR sensorgrams for the interaction of vitronectin $(\mathrm{Vn})$, at concentrations of $10 \mathrm{nM}, 5 \mathrm{nM}, 2.5 \mathrm{nM}$, $31.25 \mathrm{nM}, 0.625 \mathrm{nM}$, with immobilised WT (A), D298A (B) or $\Delta \mathrm{vWFa}$ (C) rHC1. Data are representative of 3 4 independent experiments with derived numerical values shown in Table 3. D) SPR sensorgrams for the 5 binding of TGF $\beta$-LAP proteins (TGF $\beta 1$-LAP (green); TGF $\beta 2$-LAP (orange or red); TGF $\beta 3$-LAP (purple or 6 blue)) with immobilised rHC1 (WT (light green, orange, purple) or D298A (dark green, red, blue)). The 7 individual interactions were analysed further in 3 independent experiments (using different concentrations of 8 TGF $\beta$-LAP proteins) to generate the data in Table 3. 
Figure biokxiv preprint doi: https://doi.org/10.1101/695700; this version posted July 8, 2019. The copyright holder for this preprint (which was not certified by peer review) is the authorffunder, who has granted bioBxiv a license to display the preprint in perpetuity. It is made available
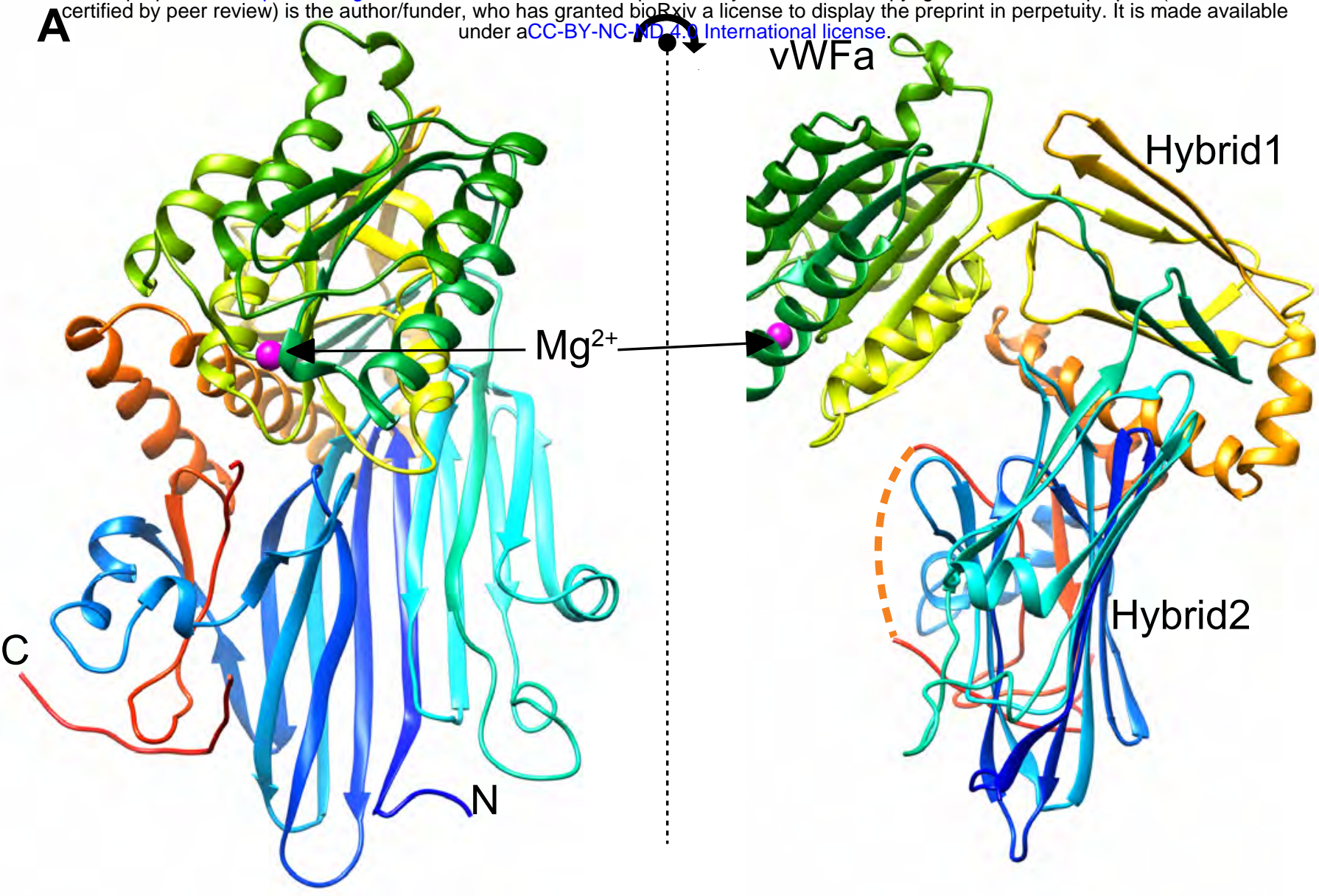

B

C

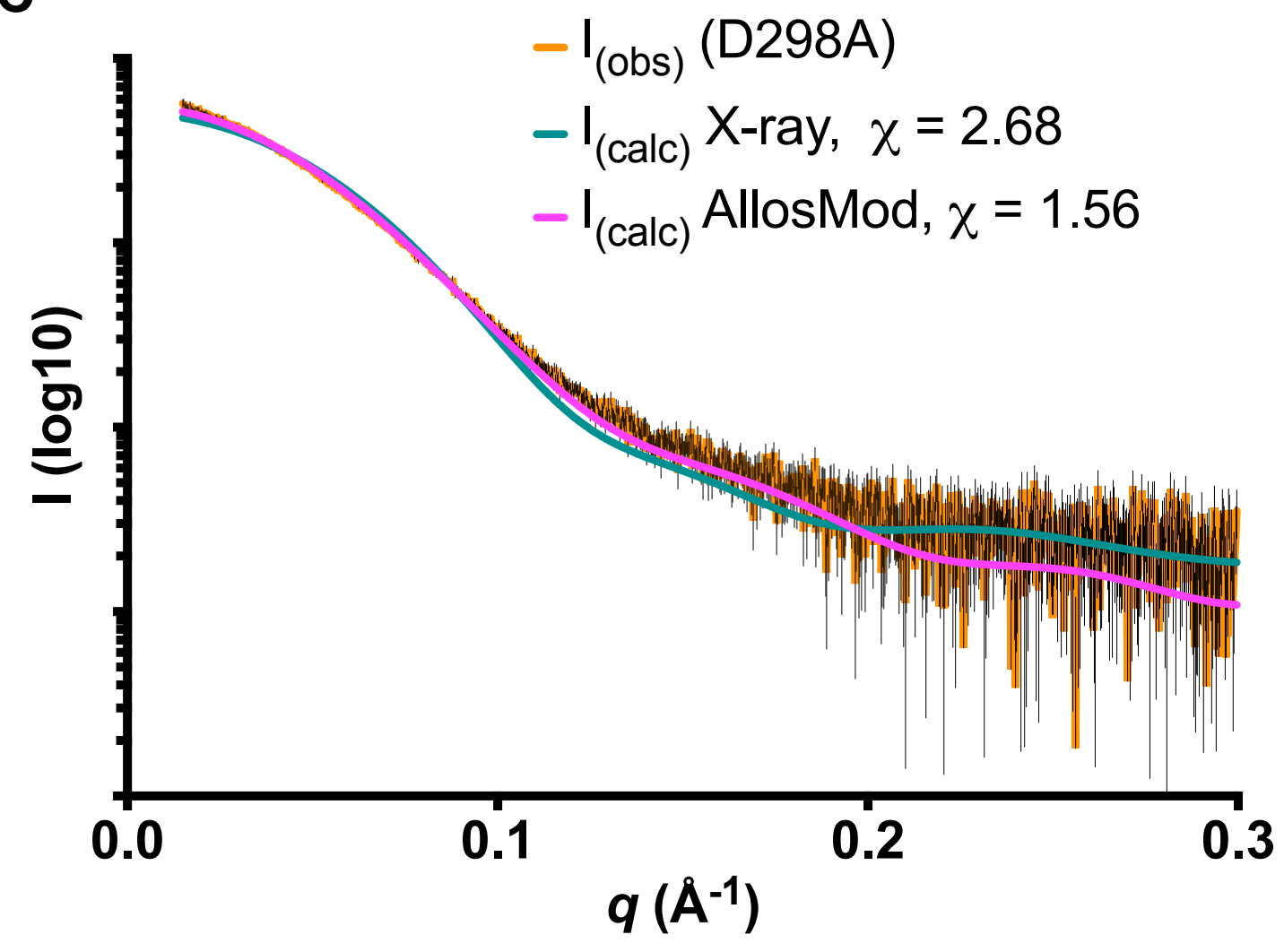

D

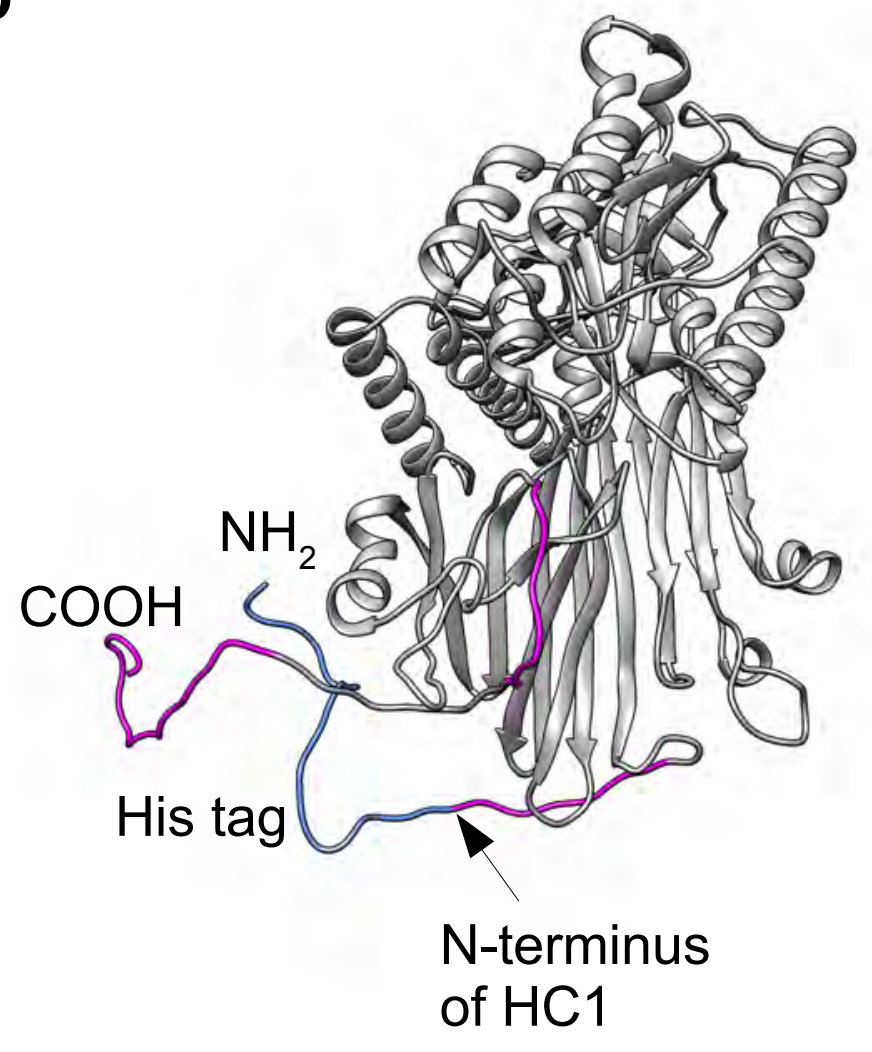



certified by peer review) is the author/funder, who has granted bioRxiv a license to display the preprint in perpetuity. It is made available Figure 2 under aCC-BY-NC-ND 4.0 International license.

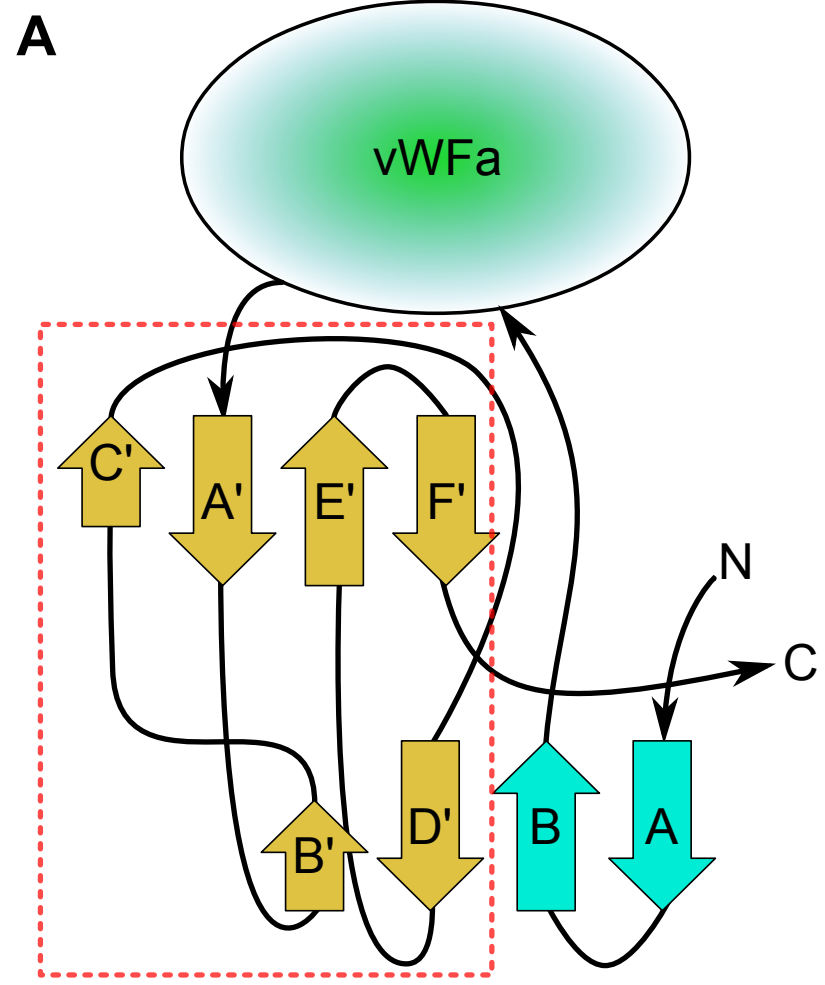

HC1 Hybrid1 domain

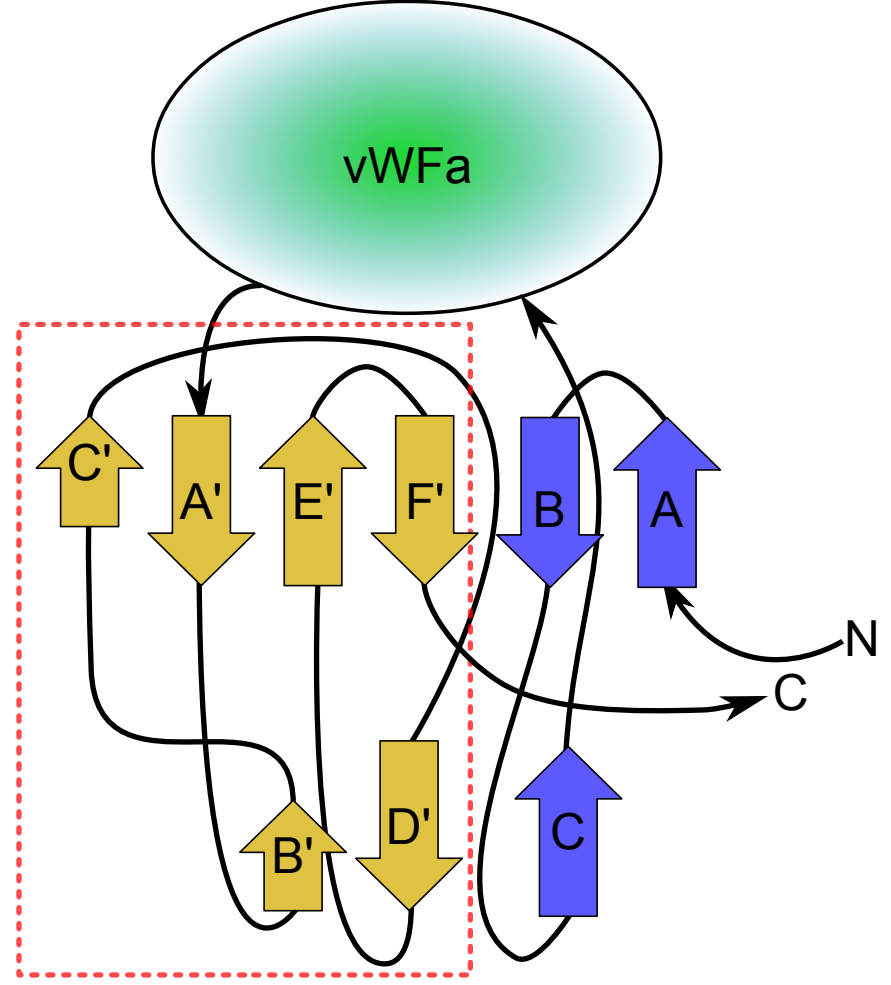

ITGB3 hybrid domain

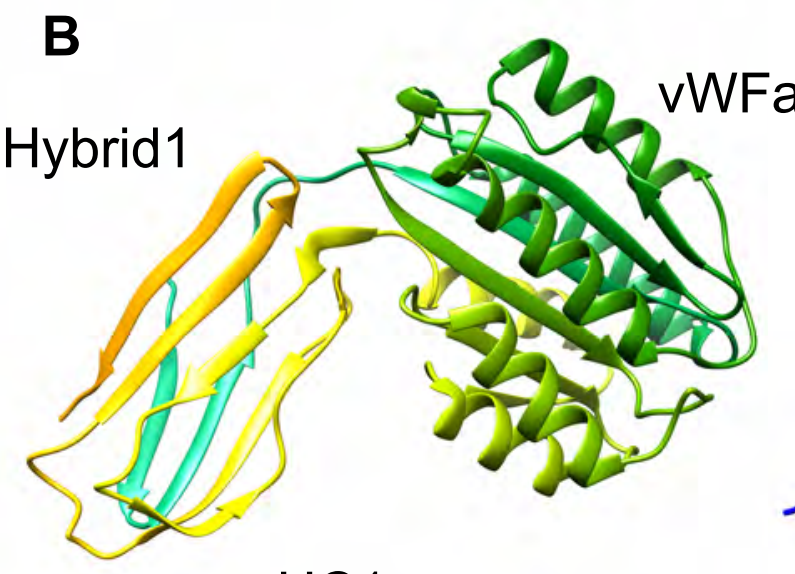

$\mathrm{HC} 1$
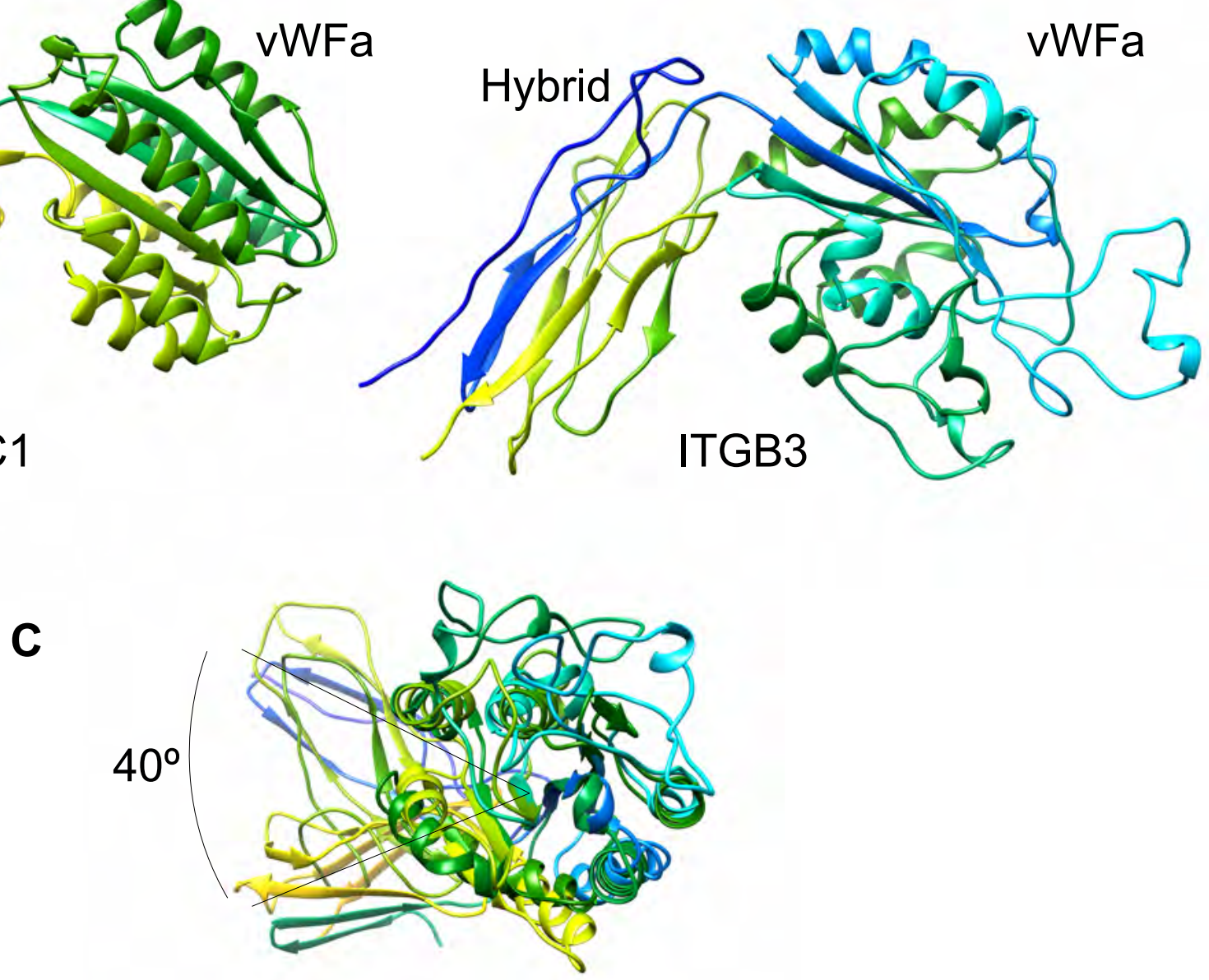
Figure 3

A

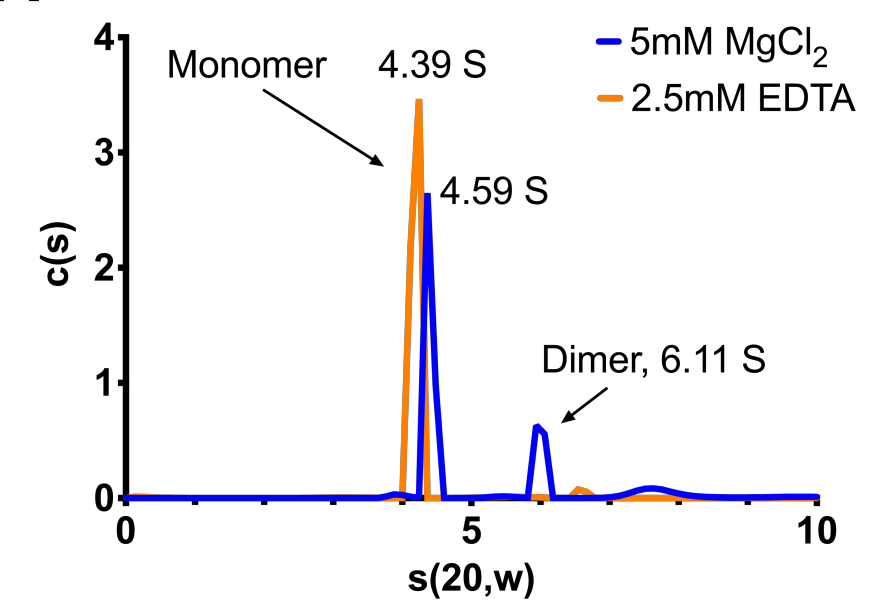

B
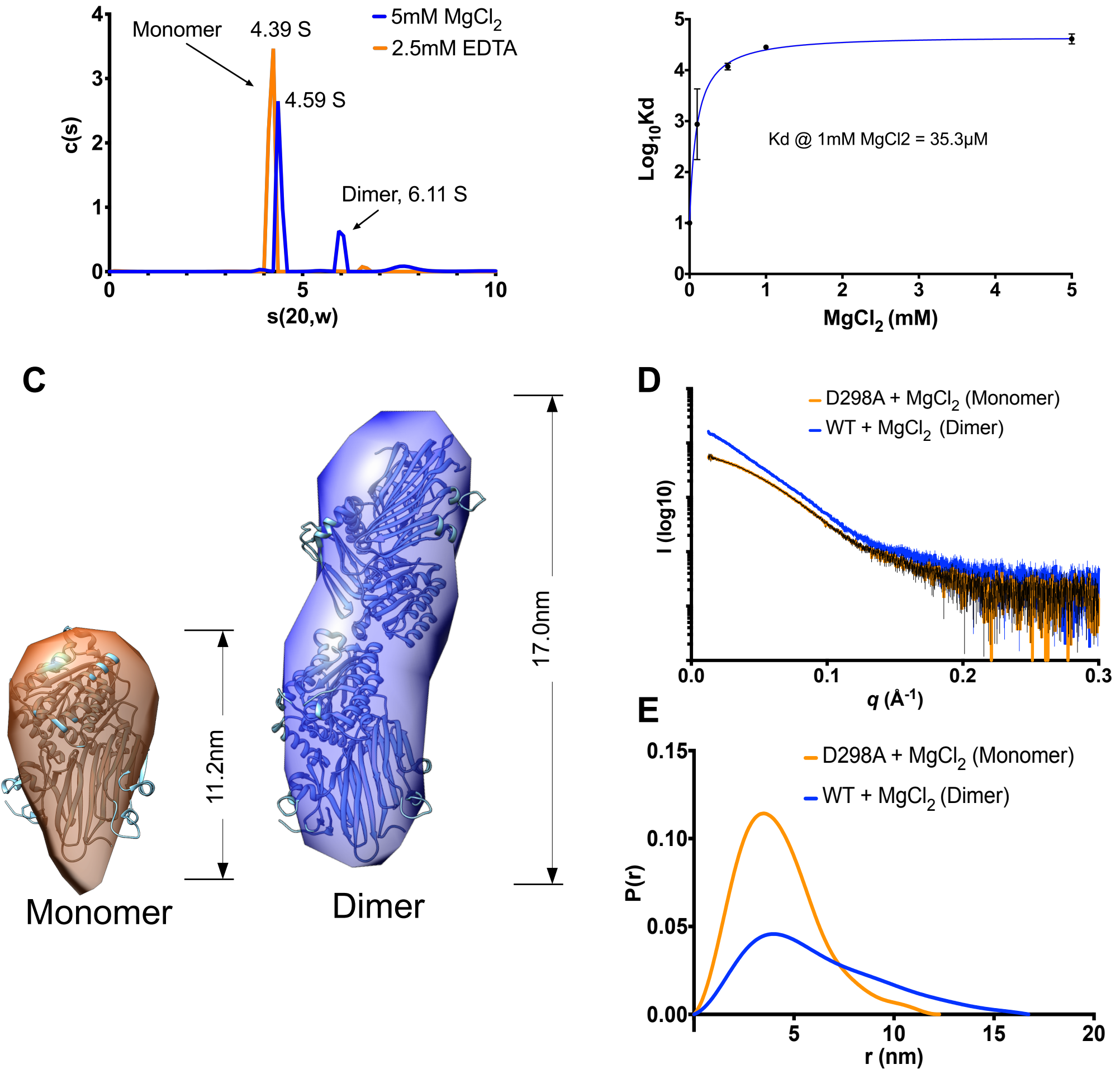

Figure 4 certified by peer review) is the author/funder, who has granted bioRxiv a license to display the preprint in perpetuity. It is made available

A
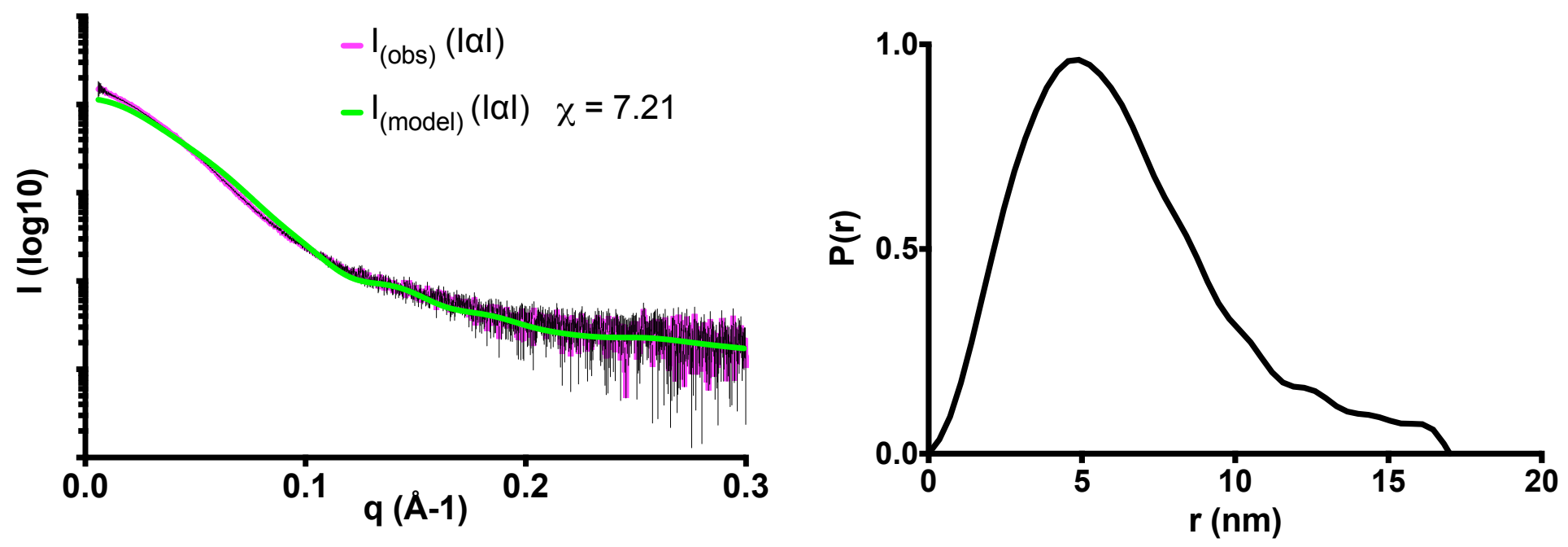

C
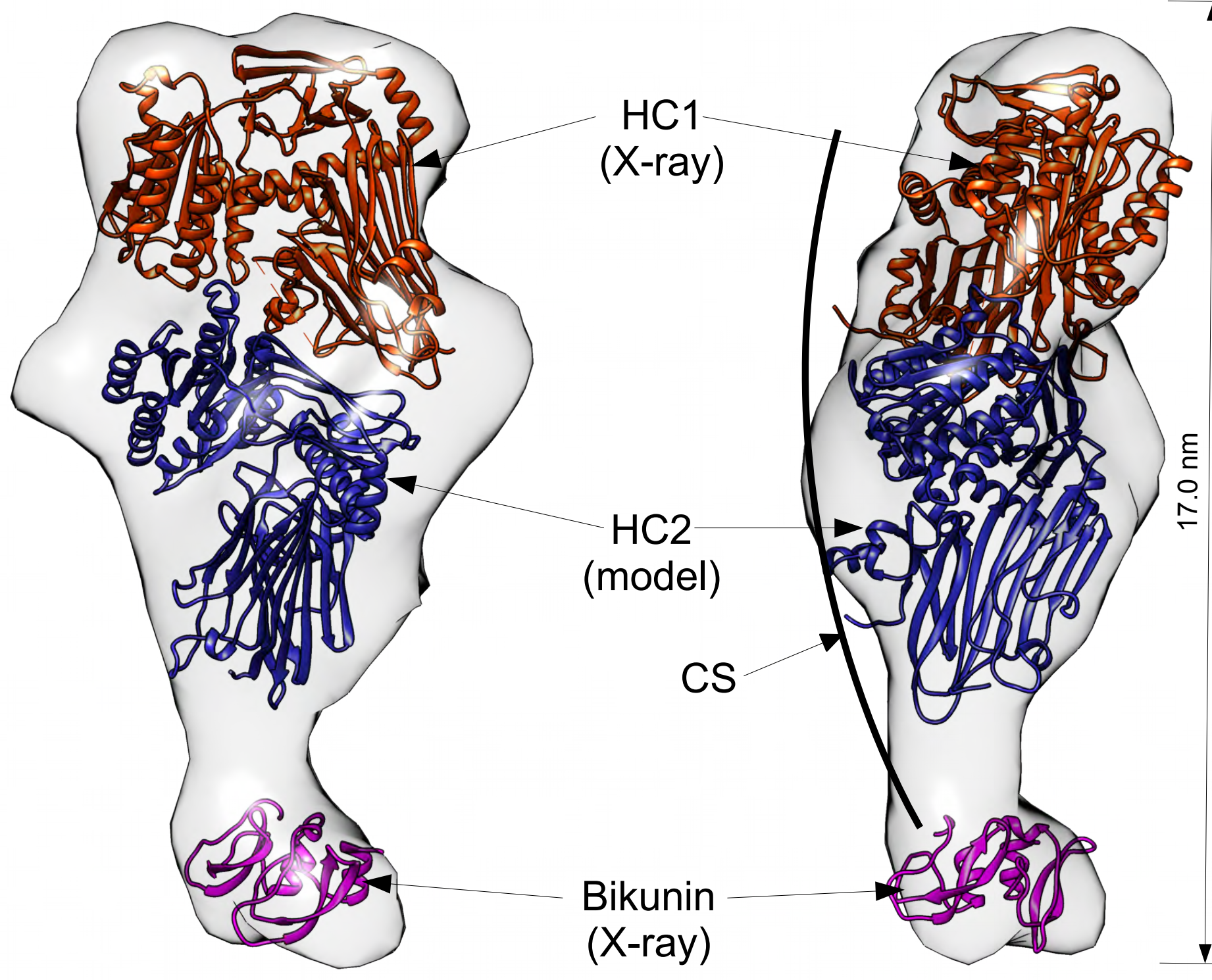
Figure 5

A

HC1 WT \& D298A binding to C3

B

$$
\text { -WT -D298A }
$$

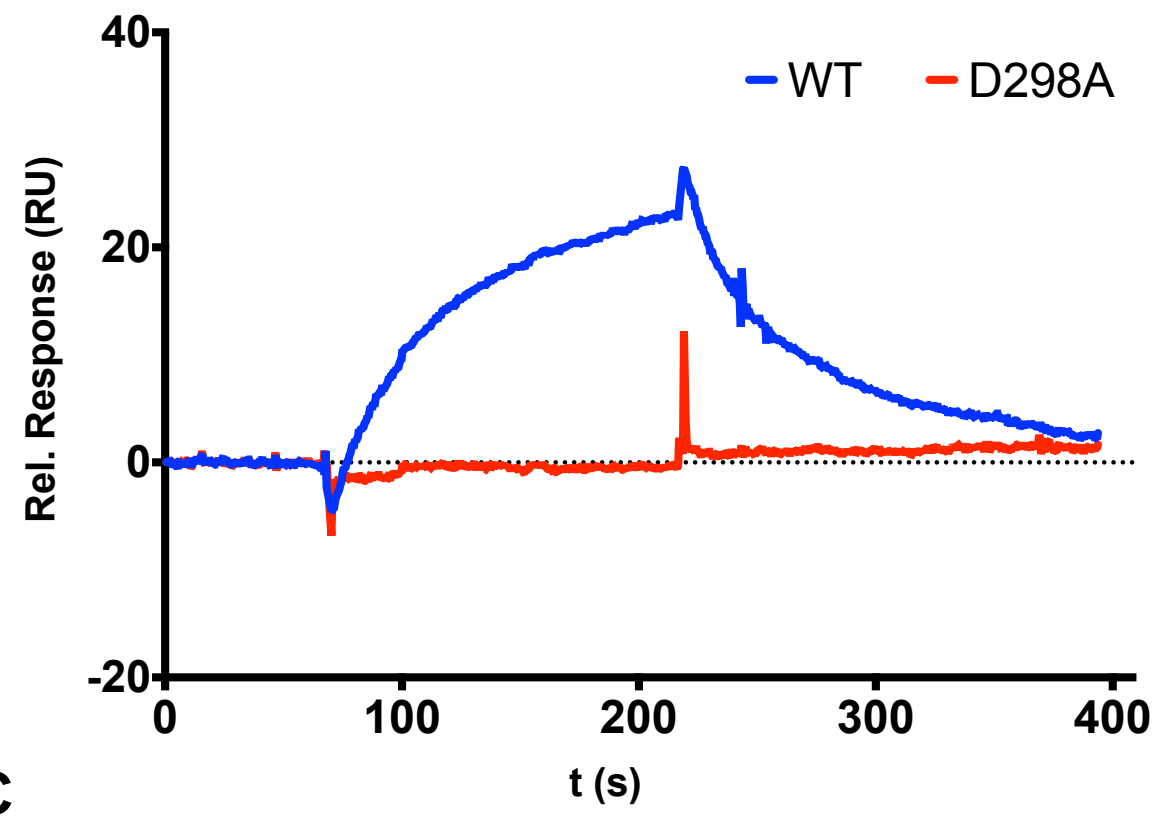

C
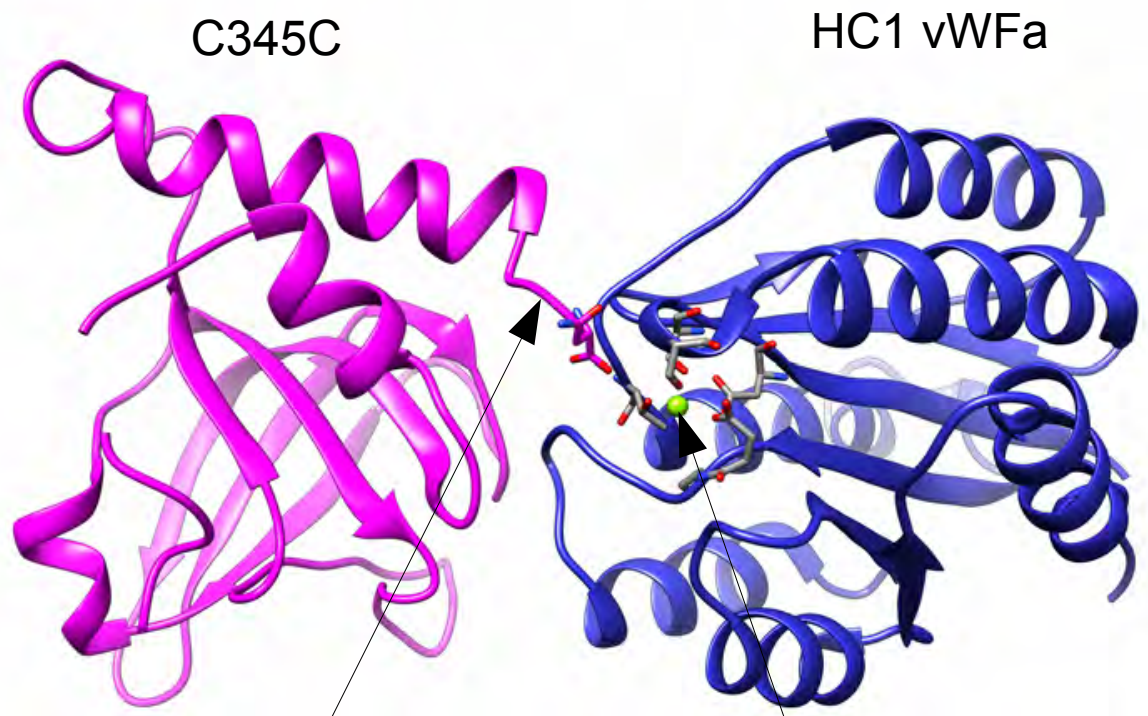

N1641

(C3 C-terminus)
HC1 vWFa

$\mathrm{Mn}^{2+}$

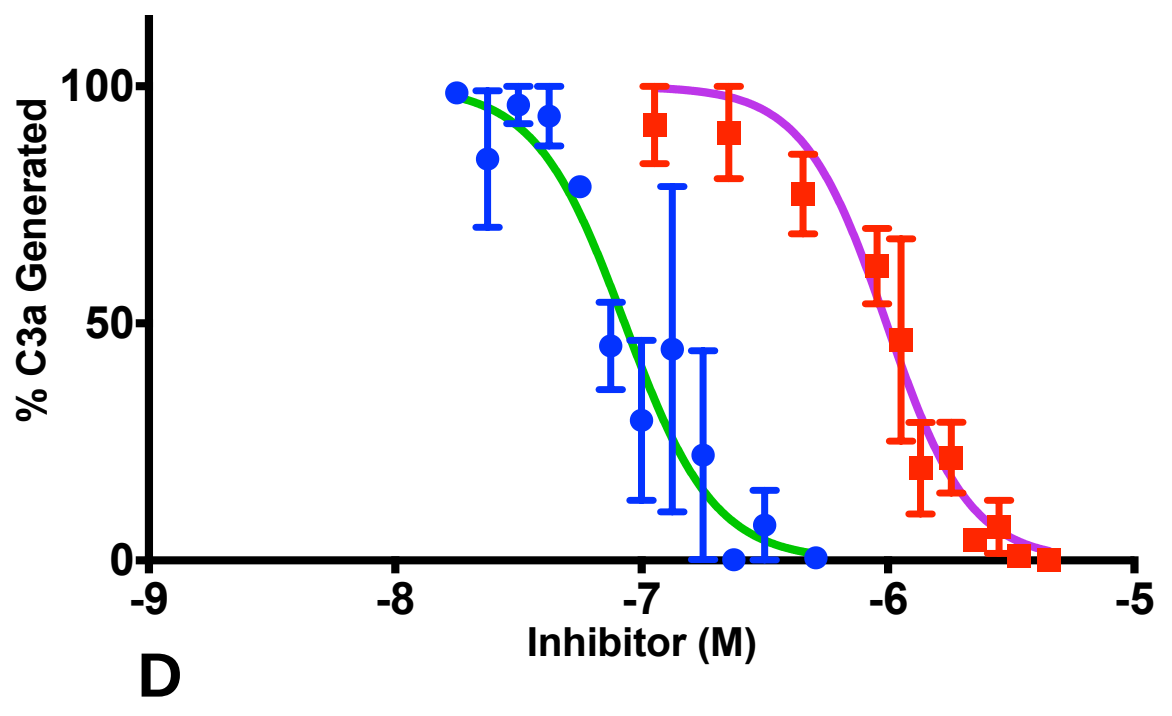

SAXS envelope

C345C HC1 vWFa

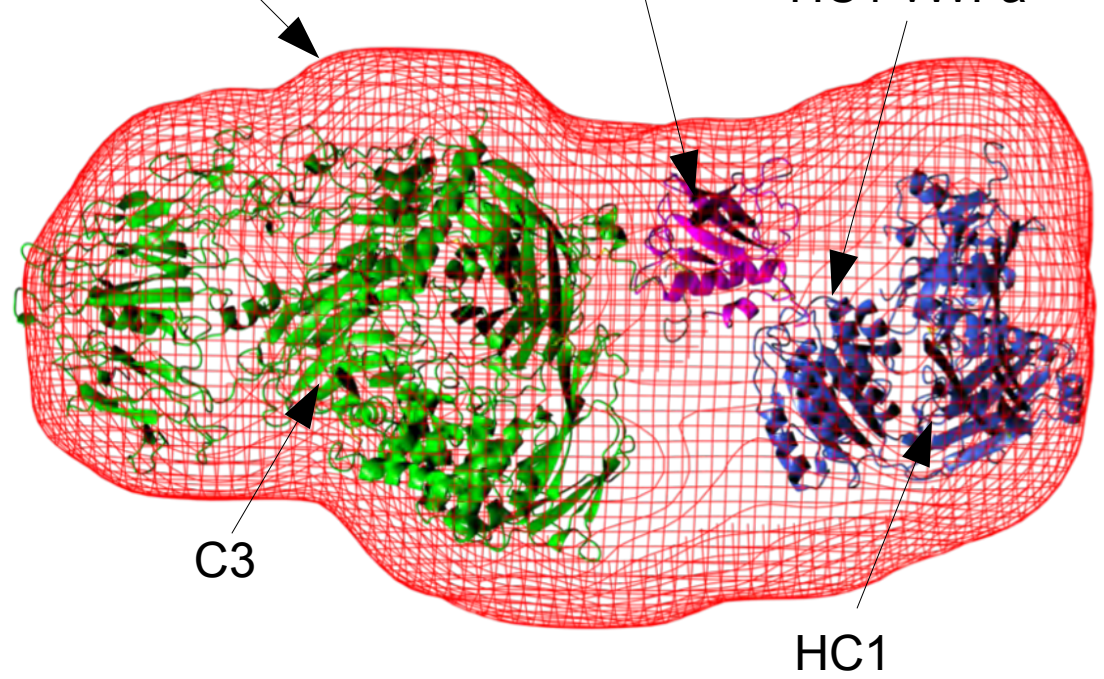

